\title{
Climate and competition affect growth and survival of transplanted sugar maple seedlings along a $1700-\mathrm{km}$ gradient
}

\author{
Rachel C. Putnam ${ }^{1,4}$ and Peter B. Reich ${ }^{2,3}$ \\ ${ }^{1}$ Department of Ecology, Evolution, and Behavior, University of Minnesota, 1987 Upper Buford Circle, \\ St. Paul, Minnesota 55108 USA \\ ${ }^{2}$ Department of Forest Resources, University of Minnesota, 1530 Cleveland Avenue North, St. Paul, Minnesota 55108 USA \\ ${ }^{3}$ Hawkesbury Institute for the Environment, Western Sydney University, Penrith, New South Wales 2753 Australia
}

\begin{abstract}
Plant species distributions, broadly shaped by climate, may also be constrained by other species. The degree to which biotic factors affect range limits is unclear, however, and few experimental studies have investigated both biotic and abiotic factors across and beyond a species' range. We examined seedling survival and net growth for three years in contrasting canopy type (closed canopy vs. gap) and neighbor density (clipped vs. unclipped) environments for northern, central, and southern populations of sugar maple (Acer saccharum) representing a climate-of-origin gradient, experimentally planted from Arkansas, USA to Ontario, Canada at ten forested sites along a 1700-km transect spanning beyond the species' range. We hypothesized that each population's highest survival and growth would occur in its region of origin, with poorer performance in cooler or warmer areas. Refuting this hypothesis, seedlings of all three populations had greater growth and survival in sites increasingly warmer than their point of origin, although they did show poorer growth and survival at increasingly colder sites. We also hypothesized that maple survival and net growth near and beyond range margins are constrained primarily by cold temperature limitation in the north, where we expected neighbors to facilitate survival, and by competition in the south, where we expected to enhance survival and growth by reducing neighbor density. Results partially supported the hypothesis concerning biotic interactions: in canopy gaps, understory neighbors enhanced maple growth at the coolest sites but did not suppress growth as expected at the warmest sites. As the northern population grew and survived reasonably well beyond the northern range limit, and as all populations performed best at warmer sites, including beyond the southern range limit, there was tepid, if any, support for the hypothesis that climate regulated the northern limit and absolutely no support for the hypothesis that competition regulated the southern limit. Together, these threeyear findings with juvenile trees suggest that sugar maple range limits may instead be constrained by factors besides climate and competition, by those factors at another life stage, and/ or by climate events such as heat waves, droughts, and cold snaps that occur at longer return intervals.
\end{abstract}

Key words: climate change; competition; facilitation; growth; northern margin; phenology; provenance; range limits; southern margin; sugar maple; survival; temperature.

\section{INTRODUCTION}

Shifts in species distribution and changes in community composition are among the likely effects of global climate change on forest ecosystems as species respond to changes in climate through altered phenology, fecundity, growth, and survival. The distributions of many plants, including woody species, are already shifting in response to changes in climate (Kullman 2002, Parmesan and Yohe 2003, Walther et al. 2005, Woodall et al. 2009, Boisvert-Marsh et al. 2014), and determining current range constraints is therefore critical to better predict and

Manuscript received 8 April 2016; revised 12 September 2016; accepted 16 September 2016. Corresponding Editor: Aimée T. Classen.

${ }^{4}$ Present address: Department of Biology, St. Olaf College, 1520 St. Olaf Avenue, Northfield, Minnesota 55057 USA. E-mail: rputnam@umn.edu understand the implications of future range shifts. Ranges reflect a species' realized niche space (sensu Hutchinson 1957), shaped by factors such as geographic barriers, species-specific climate tolerance, and interactions with other species. The degree to which biotic factors interact with climate to shape range limits, however, remains an important unresolved question in ecology (Gaston 2009, Sexton et al. 2009, Cahill et al. 2014).

Plant range limits closely parallel broad temperature and precipitation gradients (Salisbury 1926, Grace 1987, Woodward 1987, Randin et al. 2013), and climate variables are therefore frequently used to approximate species' distributions (e.g., Pither 2003, Morin et al. 2007). The widely documented range shifts associated with Quaternary climate change (Davis and Shaw 2001, Williams et al. 2004) have led to the development of some exclusively climate-based models to predict species' 
distributions in response to anticipated warming (e.g., Walker et al. 2002, Thuiller et al. 2005, McKenney et al. 2011). Projected range shifts and expansion rate estimates are improved, however, when biotic factors are included as well (Araújo and Luoto 2007, Caplat et al. 2008, Meier et al. 2010, Svenning et al. 2014), suggesting that competitive, facilitative, or mutualistic interactions with other species may play an important role in influencing species' distributions at range margins.

Greater species diversity and a more moderate climate nearer the equator led Darwin (1859) and later MacArthur (1972) to suggest that species' ranges are limited at high latitudes by climate and at lower latitudes by competition with other species. A trade-off between cold hardiness and growth rate has been hypothesized to constrain range limits (MacArthur 1972, Woodward and Pigott 1975, Loehle 1998, Aitken and Hannerz 2001, Koehler et al. 2012, Molina-Montenegro et al. 2012), but experimental and theoretical work has been insufficient to conclusively support or reject this hypothesis. Theory does suggest that competition can lead to evolutionarily stable range limits across gradual environmental gradients when evolution and environmental heterogeneity are both included in models (Case and Taper 2000, Price and Kirkpatrick 2009). Few experimental studies, however, have explicitly examined both biotic and abiotic rangelimiting factors across a full transect of the range (Parmesan et al. 2005, Sexton et al. 2009, Hargreaves et al. 2014).

Climate may impose physiological constraints on growth, reproduction, or survival that are reflected by species' range limits. Climate directly influences plant distributions through patterns of precipitation (Munson 2013) and temperature-dependent effects on plant survival and reproduction (Salisbury 1926, Grace 1987, Woodward 1987, Klimeš and Doležal 2010). Low temperature extremes may cause mortality through frost damage of stems and buds, especially if frost occurs during a phenologically vulnerable window such as budbreak (Inouye 2000, Augspurger 2009, Kollas et al. 2014). Experimental evidence for both herbaceous and woody plants suggests species also have minimum low temperatures below which they cannot produce flowers or fertilize ovules (Woodward 1990, Asselin et al. 2003), and degree of physiological cold tolerance may in turn affect the extent of species' distribution at high latitudes or altitudes (Kreyling et al. 2015). Some species have a climate tolerance broader than their current distribution (e.g., Van der Veken et al. 2007), however, suggesting that other factors may influence range limits as well.

Interspecific competition may play a role in limiting ranges for species whose distribution is not constrained by climate tolerance. Theory predicts competition for limiting resources is an important driver of variation in plant community structure and composition across environmental gradients (Tilman 1988), and competition may become an increasingly important range-limiting factor in moderate climates as species diversity and niche overlap increase (Dobzhansky 1950, MacArthur 1972, Kaufman 1995). Anecdotal evidence of competition's role at range boundaries can be found in the many species able to survive and grow in climates warmer than their equatorial range limits (Loehle 1998, Vetaas 2002) and exotic species that exceed their home-range climate envelope in island settings with fewer competing species (Sax 2001). Experimental evidence of biotic constraints on warm-edge range margins can be found in competitive interactions for both animals (e.g., Gross and Price 2000, Cunningham et al. 2009) and plants (e.g., Bullock et al. 2000, Cleavitt 2004) as well as plant-pollinator mutualisms (e.g., Moeller et al. 2012), though a review of warm-edge range limit studies found more support for abiotic than biotic limiting factors (Cahill et al. 2014).

Species' distributions may also be shaped by positive interspecific dynamics, either mutualistic or facilitative, that mitigate stressful abiotic conditions and thereby extend the realized niche (Bruno et al. 2003, Brooker et al. 2008). Fungal endophytes, for instance, allow a host grass to grow in drier regions than it would otherwise be able to occupy (Afkhami et al. 2014), while nurse trees at tree line facilitate the successful establishment of seedlings (Maher et al. 2005, Stueve et al. 2011). Neighboring vegetation may have a facilitative effect on seedling growth and survival by ameliorating effects of fall and spring frosts when seedlings are most vulnerable to cold damage (see Wipf et al. 2006), especially at northern range limits (Germino et al. 2002). Alternatively, surrounding vegetation could facilitate survival by ameliorating drought stress, as was found in a study of sugar maple in a variety of upland environments (Berkowitz et al. 1995). A study in Spain found support for both mechanisms: deciduous shrubs facilitated growth of canopy tree seedlings, protecting them from summer drought and winter frost (Gómez-Aparicio et al. 2008).

Facilitation and competition almost certainly occur simultaneously, though few studies explicitly examine both (but see Dickie et al. 2005, Montgomery et al. 2010, Wright et al. 2014). A shrub that competes with neighbors for soil nutrients and light, for example, may also facilitate neighbors by providing shade that reduces water stress. The interplay between facilitative and competitive interactions results in a continuum of net effects from strongly positive to strongly negative, and the net direction of these interactions may shift from positive to negative along environmental gradients. The stressgradient hypothesis (Bertness and Callaway 1994, Callaway and Walker 1997) proposes that facilitation increases with environmental stress, a mechanism that may be especially important at range margins (Choler et al. 2001) and under conditions to which the species is not adapted (Espeland and Rice 2007). Varying climate across a species' range modulates the context in which species interact, and under increasing cold stress, the net direction of biotic interactions may shift from competitive to facilitative (Choler et al. 2001, Callaway et al. 2002, Michalet et al. 2014). 
Reciprocal transplant experiments, which move multiple provenances to contrasting climate environments, are a time-honored method for distinguishing between genetic and environmental effects on a species' performance (e.g., Hall 1932, Hiesey 1940, Eriksson and Jonsson 1986, De Kort et al. 2014, Welk et al. 2014). There is abundant evidence that plant populations adapt to climate conditions with consequent intraspecific variation in survival and growth rates (e.g., Rehfeldt et al. 1999, McCarragher et al. 2011, Porter et al. 2013, Kreyling et al. 2014), although in some cases populations may not occupy their optimal climate niche (see Reich and Oleksyn 2008). Beyond-range experimental transfers, though uncommon, are especially valuable, as they measure growth and survival under putatively limiting climate conditions (see Levin and Clay 1984, Samis and Eckert 2009). Local adaptation in provenances near range margins may reflect selective pressures from rangelimiting constraints, informing our understanding of current distributions and how marginal populations might respond to climate change (e.g., Vergeer and Kunin 2013, Lu et al. 2014). Theory suggests the degree of local adaptation in populations at range margins is dependent on rates of dispersal and gene flow, among other factors: high gene flow from central populations may limit local adaptation at range limits (Kirkpatrick and Barton 1997), but moderate gene flow and dispersal can support local adaptation at range margins (Holt 2003).

Intraspecific variation in growth that arises from regional adaptation to climate has been noted in common garden experiments, where individuals from cold-hardy populations often grow more slowly than those from warmer sites, even when grown under common warm conditions (e.g., Savva et al. 2007, Savage and CavenderBares 2013). There is also evidence of variation among populations in response to bioticinteractions. Populations of an annual herb from contrasting light environments differed in their growth response to light competition when grown in a common garden (Dudley and Schmitt 1995), and populations of another annual herb varied in response to competition when grown with different densities of neighbors (Shaw et al. 1995). Under stressful conditions, facilitative interactions may dominate, and here too adaptive differences between populations may lead to intraspecific variation in growth (Espeland and Rice 2007). Identifying the degree of intraspecific genetic variation is important, as greater genetic diversity improves the likelihood of species' resilience to climate change (e.g., O’Neill et al. 2008, Wang et al. 2010).

Genetic variation affects each species' potential to respond to ongoing changes in climate; future distributions will be shaped by species' genetic breadth, phenotypic plasticity, mode of dispersal, and capacity to adapt in response to climate shifts (Jump and Peñuelas 2005). Relative to other plant species, trees have high levels of within-population genetic variation (Hamrick 2004) that may buffer forest species at the population level from the immediate effects of climate change (Oney et al. 2013).
Tree species, projected to lag in their response to climate change (Iverson et al. 2004), may occupy current ranges for decades to come despite mismatches between species' distributions and climate optima, since long generation times constrain migration as well as adaptation (Aitken et al. 2008). Further research is needed to identify current constraints on tree distributions and how those limits might influence species' ability to track climate through range shifts (Renwick and Rocca 2015).

Sugar maple (Acer saccharum Marsh.), a widely distributed hardwood tree species native to eastern Canada and United States, is a good candidate with which to examine the range-limiting effects of climate in the context of biotic interactions and genetic variation. Sugar maple spans a wide climate gradient and diverse forest communities, with its northern range limit coinciding with the temperate-boreal forest ecotone and its southern range limit with the mixed forests of the southeastern U.S. coastal plain (Godman et al. 1990). After migrating northward from southern refugia during the last glaciation, sugar maple's geographic distribution has been stable over the past 6000 years (Miller and Parker 2009). Genetic work on sugar maple has identified regional ecotypes that display variation in tolerance to heat and drought, onset of dormancy, chilling requirements, timing of leaf flush, and growth rate (Kriebel and Gabriel 1969). Across local temperature gradients at northern margins, sugar maple grows more slowly in colder habitats (Fisichelli et al. 2012, Reich et al. 2015), and cold temperatures have been suggested as a range-limiting mechanism (Barras and Kellman 1998). At southern margins, sugar maple is limited to a small subset of the soils it occupies in other parts of its range (Godman et al. 1990), which could both influence and be the result of competitive interactions. Though highly shade tolerant, light competition affects sugar maple seedling survival (Hett and Loucks 1971) and growth (Canham et al. 1996, Beaudet and Messier 1998). In contrast to shade intolerant species, however, competition may become important (sensu Welden and Slauson 1986) and limiting only where other abiotic stress is low and neighbor density is high (Berkowitz et al. 1995, Kunstler et al. 2011).

To determine the relative effects of abiotic and biotic factors on range limits, we conducted a three-year reciprocal transplant field experiment under natural conditions to examine the effects of climate and neighbors on sugar maple seedling survival and growth across a latitudinal transect of its range and beyond range margins. Our core hypothesis was that the range of sugar maple is constrained primarily by cold temperatures in the north and competition in the south (Fig. 1). Experimental sites spanned a climate gradient, exposing seedlings to wideranging climate conditions, and the site-level climate environment also varied from year to year; during our study, one growing season was unusually cool and wet while another was hot and dry. We planted three populations of sugar maple at all sites, sourced from northern, 
a) Hypothesis 1

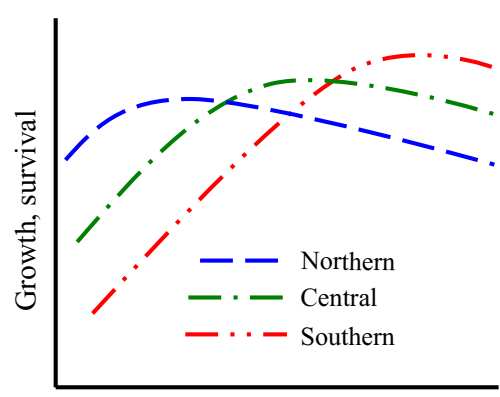

b) Hypothesis 2

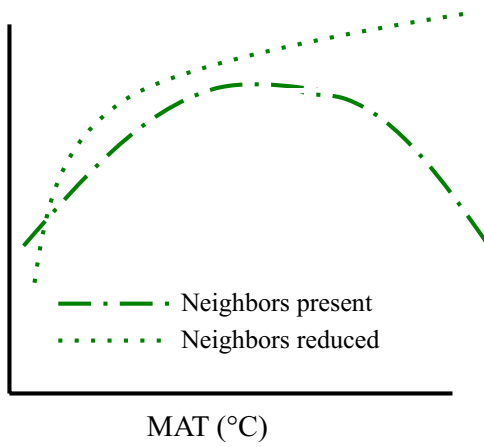

c) Hypothesis 3

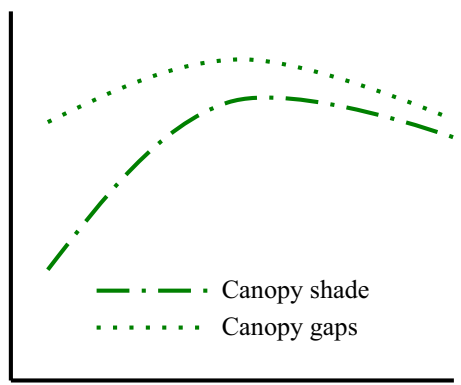

FIG. 1. Hypothesized patterns and differences in survival and growth between (a) northern, central, and southern provenances when experimentally planted along a temperature gradient, (b) seedlings planted in undisturbed forest plots and those planted in plots where understory vegetation was experimentally reduced, and (c) seedlings grown under canopy shade and those grown in gaps in the canopy. Hypothesis 1 predicts each population will have highest survival and growth in its region of origin, exhibiting a positive relationship between temperature (mean summer or winter minimum temperatures) and seedling survival or net growth up to a locally adapted optimum and a negative relationship if temperatures exceed that threshold. Hypothesis 2 predicts understory neighbors will reduce seedling survival and growth across most of the range, especially toward southern range margins, but facilitate survival and growth at the northern range margin, while hypothesis 3 predicts canopy gaps will enhance survival and growth, especially in the northern part of the range, where cooler temperatures might cause high-light gaps to be less stressful for seedlings. Hypotheses 2 and 3 are illustrated here for the central population, but similar patterns are expected across populations. As average summer (June-August) and winter (December-February) minimum temperatures are both highly correlated with mean annual temperature (MAT), we illustrate these hypotheses using MAT.

central, and southern portions of the range, and while having a single provenance from each region precludes us from drawing conclusions on population differentiation, our hypotheses on seedling performance across the range and beyond range margins were necessarily informed by provenance origin.

We hypothesized that for each of the three populations, seedling survival and net growth is nonlinearly related to summer average and winter minimum temperatures, where each population's survival and growth increases with those temperatures to a locally adapted optimum and then gradually declines with further temperature increases such that each population has highest survival and growth in the climate that mirrors that in its region of origin (H1; Fig. 1a). We further hypothesized that seedling survival and net growth is reduced by understory neighbors across most of the range, especially toward southern range margins, but facilitated at the northern range margin $(\mathrm{H} 2)$, and is enhanced in canopy gaps, especially under the cooler growing season temperatures typical of the northern part of the range (H3), as photosynthesis in gaps might be less temperature-limited than in shaded microhabitats (Fig. 1b, c).

\section{Research Methods}

\section{Study area}

In the western portion of its range, sugar maple (Acer saccharum) grows naturally from the Canadian border south to the Ozarks of Missouri (Little 1971). Sugar maple seedlings were planted at 10 sites: six sites were along a north-south latitude and climate gradient spanning the western edge of the species' range, while four sites were beyond the range margins in Ontario or Arkansas (Fig. 2). Site selection criteria were for suitable mature and relatively undisturbed forest tracts along a north-south transect where sugar maple was already present (if within the range), a criterion deemed especially important for choosing suitable sites near range margins, and where conditions such as elevation, slope, and soil type were otherwise as similar as possible. Beyond range margins, where sugar maple was absent from the forest, sites were situated where forests most closely matched the general forest type within the range.

Experimental sites spanned $1700 \mathrm{~km}$ and a temperature gradient characterized by a $14^{\circ} \mathrm{C}$ spread in mean annual temperature $\left(2.1-16.1^{\circ} \mathrm{C}\right)$ and $9.8^{\circ} \mathrm{C}$ difference in average June-August (hereafter referred to as summer) temperatures $\left(16.1^{\circ}-25.9^{\circ} \mathrm{C}\right.$; Table 1$)$. Average summer soil moisture availability is lower at southern than northern sites due to greater potential evapotranspiration (Table 1); average precipitation totals for June-August vary from 265 to $303 \mathrm{~mm}$ across sites with no clear latitudinal trend (Appendix S1: Fig. S1). While all sites had loam soils (Table 1), the scale of the geographic gradient spanned by sites made variation in soil texture, type, and $\mathrm{pH}$ unavoidable. At within-range sites, soils were alfisols, while soils at beyond-range sites were ultisols (southern sites) or brunisols (northern sites; Table 1). Sites in Minnesota, Iowa, and Missouri also had deep loess soils capping glacial deposits that contrasted with the cherty or gravelly loams of Arkansas and the shallow soils overlying glacial till and glacial lacustrine deposits in Ontario. Soils ranged in $\mathrm{pH}$ from 4.14 to 6.81 , with more basic soils in the central region of the study area (Table 1). 


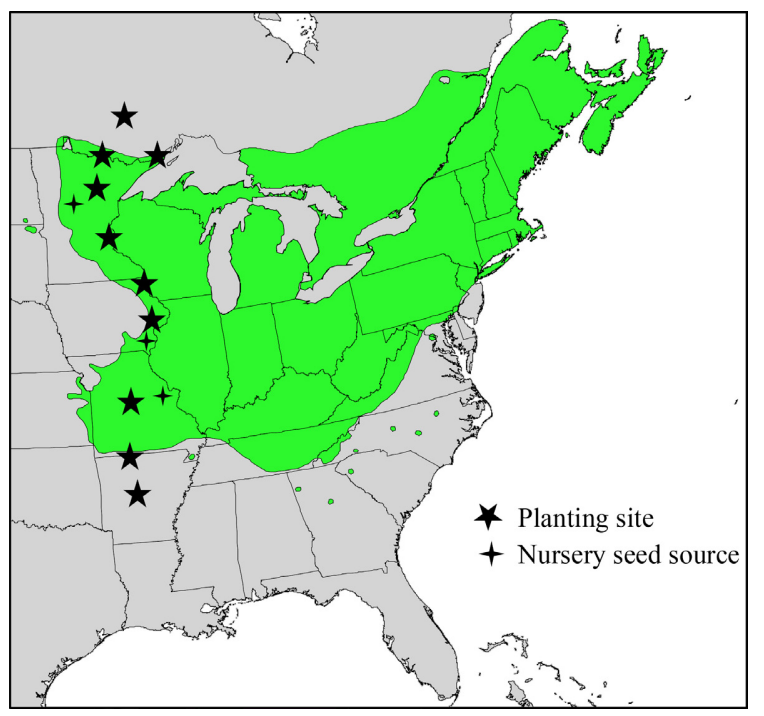

FIG. 2. Range map for sugar maple (Acer saccharum), adapted from Little (1971). In the western portion of its range, sugar maple can be found from southern Missouri, USA to the Minnesota, USA-Ontario, Canada border. Nursery-grown seedlings were sourced from populations in Minnesota, Iowa, and Missouri and planted at 10 sites along a north-south transect of the western edge of the species' range and beyond range margins to the north and south.

Sites were located in mature hardwood or hardwooddominated forests under federal, state, provincial, and private ownership. At southern sites, forest canopies were dominated by oaks (Quercus alba, Q. elutina, Q. ubra), hickories (principally Carya ovata), and tupelo (Nyssa sylvatica). Pines were abundant at two sites: Pinus echinata at the southernmost site, and $P$. trobus at a centrally located site. The central portion of the study area had diverse forests dominated by mesic hardwood species such as sugar maple (Acer saccharum), basswood (Tilia americana), black walnut (Juglans nigra), and slippery elm (Ulmus rubra), as well as oaks ( $Q . l b a, Q . u b r a)$, while forest canopies at northern sites were dominated by species characteristic of the boreal forest: quaking aspen (Populus tremuloides), paper birch (Betula papyrifera), black ash (Fraxinus nigra), and balsam fir (Abies balsamea). Forests had not been recently burned or logged, though an ice storm in Arkansas a few years prior had thinned the forest canopy at one site. Most sites were located on moderate slopes $\left(14^{\circ}-32^{\circ}\right)$, but northern sites (DRYD, PIKE, FORT, TBAY) had little slope $\left(4^{\circ}-16^{\circ}\right)$. Site elevation, ranging between 193 and $419 \mathrm{~m}$, did not differ systematically with latitude.

\section{Experimental design}

To identify population-specific responses to both local and novel climate and neighbors, seedlings from three sugar maple populations were planted at each site. Oneyear-old field-grown seedlings were purchased from three commercial nurseries whose seed sources were sugar maple populations in Mille Lac County, Minnesota $\left(5.3^{\circ} \mathrm{C}\right.$ mean annual temperature [MAT]), Lee County, Iowa $\left(11.1^{\circ} \mathrm{C} \mathrm{MAT}\right)$, and Lincoln County, Missouri $\left(12.4^{\circ} \mathrm{C}\right.$ MAT), respectively; Table 2 details region-oforigin climate data for each population. The populations (referred to here as northern, central, and southern) all came from the western part of the range, where sugar maple tends to be more drought tolerant than eastern populations (Kriebel and Gabriel 1969). Within this broad regional ecotype, temperature has a greater effect on growth than precipitation (Lane et al. 1993), and there is evidence of genetic variation from north to south (Gunter et al. 2000).

Prior to leaf-out, seedlings were planted at 48 stratified randomly selected plots within the forest interior at each of the 10 sites in the spring of 2009. Plots were situated such that all trees within $1.5 \mathrm{~m}$ of plot center were less than $10 \mathrm{~cm}$ dbh (diameter at breast height). To determine the effects of biotic interactions on sugar maple survival and growth, we measured both overstory light availability and aboveground competition with understory neighbors. Plots were randomly assigned contrasting canopy cover types: one-half of the plots were located in small pre-existing canopy gaps, many of which were created by recent tree-falls, while remaining plots were located under a closed forest canopy. One-half of the plots in each canopy cover type were assigned a clipping treatment where neighbor abundance was reduced through annual clipping treatments, while the remaining plots were left unclipped. There were 12 replicate plots for each of four treatment combinations: open canopy (gap) or closed canopy (shade) plots, with or without neighbor removal (clip or no clip), a total of 48 plots and 144 seedlings per site.

Three seedlings (one from each source population) were planted in each plot, protected from deer browsing by individual fine plastic mesh sleeves and spaced $0.5 \mathrm{~m}$ from each other and from plot center. Relative abundance of herbaceous vegetation within a $1-\mathrm{m}$ radius of plot center (estimated by percent cover) and abundance of woody vegetation within a $2-\mathrm{m}$ radius of plot center (speciesspecific stem counts within size classes based on diameter and height) were used to characterize understory neighborhoods in each plot. In clip plots, all herbaceous understory vegetation within a $1-\mathrm{m}$ radius from plot center and all woody shrubs and saplings within a 2-m radius of plot center were then clipped at ground level. In the remaining plots, vegetation was left intact surrounding planted sugar maple seedlings. All clip plots were clipped annually to maintain the treatment; plots where regrowth was strongest (vegetation over $15 \mathrm{~cm}$ covered more than $25 \%$ of the plot) were clipped twice annually, but this was necessary only at a subset of sites and plots. Clipped biomass was recorded and then removed from the plot to prevent fertilization effects from decaying biomass. Clip plots were not root trenched, as the clipping treatment was designed to reduce neighbor interactions with understory vegetation, not canopy trees. 
TABLE 1. Summary of annual and summer (June-August) climate data (calculated from 30-year climate normals, 1971-2000) and canopy light and soil characteristics typical of each site.

\begin{tabular}{|c|c|c|c|c|c|c|c|c|c|c|}
\hline \multirow[b]{2}{*}{ Site } & \multirow[b]{2}{*}{$\begin{array}{l}\text { Lat., } \\
\text { Long. }\end{array}$} & \multicolumn{2}{|c|}{ Annual } & \multicolumn{3}{|c|}{ Summer } & \multicolumn{2}{|c|}{ Light ( $\%$ full) } & \multicolumn{2}{|l|}{ Soil } \\
\hline & & $\begin{array}{l}\text { Temp. } \\
\left({ }^{\circ} \mathrm{C}\right)\end{array}$ & $\begin{array}{l}\mathrm{PPT} \\
(\mathrm{mm})\end{array}$ & $\begin{array}{l}\text { Temp. } \\
\left({ }^{\circ} \mathrm{C}\right)\end{array}$ & $\begin{array}{l}\text { PPT } \\
(\mathrm{mm})\end{array}$ & $\begin{array}{l}\text { Moisture } \\
\text { availability }\end{array}$ & Shade & Gap & $\begin{array}{l}\text { Order, } \\
\text { texture }\end{array}$ & $\mathrm{pH}$ \\
\hline $\begin{array}{l}\text { Jessieville, Arkansas, } \\
\text { Alum Creek Experimental } \\
\text { Forest (ALUM) }\end{array}$ & $\begin{array}{l}34.8^{\circ} \mathrm{N}, \\
93.0^{\circ} \mathrm{W}\end{array}$ & 16.1 & 1569 & 25.9 & 309 & 0.69 & 9.2 & 17.2 & $\begin{array}{l}\text { ultisol, } \\
\text { loam }\end{array}$ & 4.14 \\
\hline $\begin{array}{l}\text { Jasper, Arkansas, } \\
\text { Henry R. Koen Exp. } \\
\text { Forest (KOEN) }\end{array}$ & $\begin{array}{l}36.0^{\circ} \mathrm{N}, \\
93.2^{\circ} \mathrm{W}\end{array}$ & 14.4 & 1196 & 24.6 & 257 & 0.62 & 9.7 & 23.2 & $\begin{array}{l}\text { ultisol, } \\
\text { silt loam }\end{array}$ & 4.62 \\
\hline $\begin{array}{l}\text { Ashland, Missouri, } \\
\text { Baskett Research \& } \\
\text { Education Area (BREA) }\end{array}$ & $\begin{array}{l}38.7^{\circ} \mathrm{N} \\
92.2^{\circ} \mathrm{W}\end{array}$ & 12.5 & 1023 & 24.4 & 294 & 0.69 & 5.3 & 12.8 & $\begin{array}{l}\text { alfisol, } \\
\text { silt loam }\end{array}$ & 4.80 \\
\hline $\begin{array}{l}\text { Muscatine, Iowa, } \\
\text { Wildcat Den State Park } \\
\text { (WILD) }\end{array}$ & $\begin{array}{l}41.5^{\circ} \mathrm{N} \\
90.9^{\circ} \mathrm{W}\end{array}$ & 10.3 & 912 & 23.0 & 325 & 0.82 & 6.8 & 22.2 & $\begin{array}{l}\text { alfisol, } \\
\text { silt loam }\end{array}$ & 6.54 \\
\hline $\begin{array}{l}\text { New Albin, Iowa, } \\
\text { Fish Farm Mounds State } \\
\text { Preserve (FISH) }\end{array}$ & $\begin{array}{l}43.5^{\circ} \mathrm{N} \\
91.3^{\circ} \mathrm{W}\end{array}$ & 7.8 & 853 & 21.4 & 334 & 0.99 & 5.4 & 11.5 & $\begin{array}{l}\text { alfisol, } \\
\text { sandy loam }\end{array}$ & 6.81 \\
\hline $\begin{array}{l}\text { Marine-on-St. Croix, } \\
\text { Minnesota, } \\
\text { Pine Needles tract (PINE) }\end{array}$ & $\begin{array}{l}45.2^{\circ} \mathrm{N} \\
92.8^{\circ} \mathrm{W}\end{array}$ & 7.2 & 815 & 20.6 & 344 & 1.00 & 6.3 & 20.2 & $\begin{array}{l}\text { alfisol, } \\
\text { sandy loam }\end{array}$ & 6.75 \\
\hline $\begin{array}{l}\text { Cass Lake, Minnesota, } \\
\text { Pike Bay Experimental } \\
\text { Forest (PIKE) }\end{array}$ & $\begin{array}{l}47.3^{\circ} \mathrm{N} \\
94.5^{\circ} \mathrm{W}\end{array}$ & 3.9 & 670 & 18.6 & 302 & 1.07 & 4.7 & 9.3 & $\begin{array}{l}\text { alfisol, } \\
\text { loam }\end{array}$ & 5.10 \\
\hline $\begin{array}{l}\text { Neebing, Ontario, } \\
\text { Private land } \\
\text { (TBAY) }\end{array}$ & $\begin{array}{l}48.3^{\circ} \mathrm{N}, \\
89.4^{\circ} \mathrm{W}\end{array}$ & 2.5 & 712 & 16.1 & 249 & 1.19 & 5.9 & 18.0 & $\begin{array}{l}\text { brunisol, } \\
\text { sandy loam }\end{array}$ & 5.18 \\
\hline $\begin{array}{l}\text { Fort Frances, Ontario, } \\
\text { Crown land } \\
\text { (FORT) }\end{array}$ & $\begin{array}{l}48.8^{\circ} \mathrm{N}, \\
93.4^{\circ} \mathrm{W}\end{array}$ & 2.9 & 721 & 17.4 & 300 & 1.20 & 9.2 & 30.2 & $\begin{array}{l}\text { brunisol, } \\
\text { sandy loam }\end{array}$ & 4.55 \\
\hline $\begin{array}{l}\text { Dryden, Ontario, } \\
\text { Crown land } \\
\text { (DRYD) }\end{array}$ & $\begin{array}{l}49.9^{\circ} \mathrm{N}, \\
92.3^{\circ} \mathrm{W}\end{array}$ & 2.1 & 701 & 17.4 & 287 & 1.13 & 11.1 & 36.1 & $\begin{array}{l}\text { brunisol, } \\
\text { sandy loam }\end{array}$ & 4.53 \\
\hline
\end{tabular}

Notes: Climate data were obtained from the PRISM Climate Group of Oregon State University (for the seven sites in the United States) and the Canadian National Climate Data and Information Archive (for the three sites in Ontario, Canada). Summer moisture availability (precipitation, PPT, divided by potential, PET) was calculated using equations from Thornthwaite (1948). Average percent light penetrating the canopy at each site was calculated by averaging plot-level densiometer readings across years for each canopy type. Soil orders were determined from soil maps, while soil texture and $\mathrm{pH}$ were measured in the lab from soil samples collected at each site in 2011. Lat., latitude; Long., longitude; Temp., mean temperature.

\section{Seedling measurements}

Initial seedling height, measured from root collar to tallest branch prior to planting in the spring of 2009 , ranged from 50 to $590 \mathrm{~mm}$, while seedling diameter at the root collar ranged from 2 to $12 \mathrm{~mm}$. Average initial seedling height and diameter differed considerably among the populations (114 and $4.1 \mathrm{~mm}, 258$ and $4.8 \mathrm{~mm}$, and 329 and $7.1 \mathrm{~mm}$ for the central, northern, and southern populations, respectively), but there was a fair amount of overlap among the populations in the distribution of initial sizes (Appendix S1: Fig. S2). Seedling height, diameter, stem extension (the sum of new growth on all branches), and dieback (the sum of recent mortality

TABLE 2. Climate-of-origin data for the three populations in this field experiment, based on 30-year climate normals (1981-2010) obtained from the PRISM Climate Group of Oregon State University.

\begin{tabular}{|c|c|c|c|c|c|c|c|c|}
\hline \multirow[b]{2}{*}{ Population } & \multirow[b]{2}{*}{ Lat., Long. } & \multirow[b]{2}{*}{$\begin{array}{l}\text { Elevation } \\
\text { (m) }\end{array}$} & \multicolumn{3}{|c|}{ Annual } & \multicolumn{3}{|c|}{ Summer (June-August) } \\
\hline & & & Temp. $\left({ }^{\circ} \mathrm{C}\right)$ & PPT (mm) & $\begin{array}{l}\text { Moisture } \\
\text { availability }\end{array}$ & Temp. $\left({ }^{\circ} \mathrm{C}\right)$ & PPT (mm) & $\begin{array}{c}\text { Moisture } \\
\text { availability }\end{array}$ \\
\hline North & $\begin{array}{l}45.905^{\circ} \mathrm{N} \text {, } \\
93.574^{\circ} \mathrm{W}\end{array}$ & 368 & 5.3 & 781 & 1.34 & 19.3 & 322 & 0.88 \\
\hline Central & $\begin{array}{l}40.612^{\circ} \mathrm{N} \\
91.682^{\circ} \mathrm{W}\end{array}$ & 176 & 11.3 & 978 & 1.34 & 23.7 & 329 & 0.77 \\
\hline South & $\begin{array}{l}39.025^{\circ} \mathrm{N} \\
90.93^{\circ} \mathrm{W}\end{array}$ & 179 & 12.6 & 1,031 & 1.36 & 24.3 & 290 & 0.67 \\
\hline
\end{tabular}

Notes: Moisture availability (PPT/PET) was calculated using equations from Thornthwaite (1948). Seedlings were purchased from three nurseries whose seed sources were sugar maple populations in Mille Lacs County, Minnesota, Lee County, Iowa, and Lincoln County, Missouri (north, central, and south populations, respectively). 
on all branches) were all measured annually in mid to late summer after growth for the season was complete. Seedling survival was assessed twice annually: spring survival data reflected overwintering mortality, while the mid to late summer visit captured growing-season mortality. A variety of seedling health metrics, such as leaf and stem damage due to insects, mammal herbivory, and disease, were also assessed twice annually. In the spring and fall of 2011, trained volunteers collected phenology data at two sites spanning a $10.5^{\circ} \mathrm{C}$ difference in MAT (Table 1): a cold-climate northern site (Cass Lake, Minnesota) and a warm-climate southern site (Jasper, Arkansas). The timing and frequency of phenology visits varied, reflecting contrasting growing season length at the two sites and the challenge of maintaining consistency with volunteers: spring leaf-out was recorded over four visits from mid-March to mid-April at the southern site and two visits in May at the northern site, while leaf senescence was recorded over three visits at the northern site in September and October and a single visit at the southern site in November. After three growing seasons and winters and before growth for the next season had commenced, all living seedlings were dug up in early spring 2012 and harvested in their entirety; they were then kiln dried at $75^{\circ} \mathrm{C}$ and total seedling dry mass was calculated from separate measurements of root and shoot mass.

\section{Site and plot conditions}

Temperature and precipitation data for all sites in the United States were obtained from the PRISM Climate Group (Oregon State University); PRISM model output is based on weather station data, interpolated using local data such as elevation, and is accurate to $2 \mathrm{~km}$ (data available online) ${ }^{5}$ For the three sites in Ontario, climate data were obtained from weather stations nearest to each site via the Canadian National Climate Data and Information Archive (Government of Canada); data accuracy ranges from 15 to $24 \mathrm{~km}$ (data available online). ${ }^{6}$ Averaged over the three years of the experiment, summer temperature and precipitation and winter minimum temperature approximated the 30-year climate normals at most sites (Table 3), but the first year of the experiment was cooler and wetter than average across the range, while the third year was hotter and drier and the winter was milder than average (Appendix S1: Fig. S1). Though site latitude generally reflected the gradient in temperature across sites, one site at the northern range margin (in Neebing, Ontario) was cooler in summer and warmer in winter than either beyond-range site at higher latitudes due to lake effect.

Tree density in the immediate vicinity of each plot was assessed using a 10-factor wedge prism to estimate basal area of canopy neighbors: per standard procedure, basal

\footnotetext{
${ }^{5} \mathrm{http}: / /$ prism.oregonstate.edu

${ }^{6} \mathrm{http}: / /$ climate.weather.gc.ca
}

area estimates included all trees that were "in" and half of those that were "borderline" when viewed from plot center. Average basal area varied by site but was greater in shade plots $\left(20.8-40.2 \mathrm{~m}^{2} / \mathrm{ha}\right)$ than in gap plots $(17.7-$ $\left.34.2 \mathrm{~m}^{2} / \mathrm{ha}\right)$, and at within-range sites $\left(31.3 \mathrm{~m}^{2} / \mathrm{ha}\right)$ than at the southernmost or northernmost sites $\left(23.5 \mathrm{~m}^{2} / \mathrm{ha}\right)$. Forest canopies in the north were also patchier, and the difference between gap and shade plots in the density of the surrounding forest canopy increased with latitude. Site-level species richness of canopy trees in plot neighborhoods ranged from 10 to 28 species, with a median of 18 species per site, while across sites, the average number of tree species in the plot neighborhood varied from 2.40 to 4.75 . On average, the three most abundant species at a site were responsible for $74 \%$ of the basal area of the forest.

The herbaceous and woody components of the understory neighborhood in each plot were characterized separately. Percent cover of herbaceous vegetation varied by site and through the growing season, though there was no clear pattern across latitude. At planting time in 2009, site averages of percent herbaceous cover ranged from less than $10 \%$ to more than $90 \%$; sites with less herbaceous cover tended to have more cover from understory woody species. In the south, the woody understory was comprised of tree species such as red maple (Acer rubrum), flowering dogwood (Cornus florida), and pawpaw (Asimina triloba), as well as shrubs such as blueberry (Vaccinium sp.), spice bush (Lindera benzoin), poison ivy (Toxicodendron radicans), and fragrant sumac (Rhus aromatica), while in the north, the understory was dominated by mountain maple (Acer spicatum), balsam fir (Abies balsamea), and hazelnut (Corylus sp.), along with northern bush honeysuckle (Diervilla lonicera), currant (Ribes sp.), and raspberry (Rubus sp.). At sites where it was present, sugar maple was often very abundant in the understory. Basal area of the woody understory ranged from an average of $1.85 \mathrm{~cm}^{2} / \mathrm{m}^{2}$ at southern and central sites to $4.95 \mathrm{~cm}^{2} / \mathrm{m}^{2}$ at northern sites.

Canopy openness above each plot was measured with a densiometer; readings were taken at a height of one meter and at plot center rather than at each seedling, as the purpose was to quantify general light availability for both seedlings and understory neighbors. Light environments varied from site to site, especially in gaps: in gaps, average canopy openness ranged from $9 \%$ to $36 \%$ across sites, while average canopy openness in shade plots ranged from $4 \%$ to $10 \%$. Compared with shade plots, gaps averaged 2.5 times more light at southern sites and 3.4 times more light at northern sites, where canopy gaps tended to be larger.

The clip treatment was effective in reducing the density of understory neighbors over time. Following the initial clipping, neighbor density was reduced in clip plots in subsequent years compared to unclipped plots, and annual maintenance clipping further reduced average standing biomass in plots. In 2011, clip plots averaged 17\% less herbaceous vegetation prior to re-clipping than no-clip 
TABLE 3. Summary of climate data (mean summer [JJA] temperature, cumulative summer precipitation, and winter [DJF] minimum temperature $\left[T_{\mathrm{min}}\right]$, with SD) for each site, comparing climate normals (1971-2008) and the years of the experiment (2009-2011).

\begin{tabular}{|c|c|c|c|c|c|c|c|}
\hline \multirow[b]{2}{*}{ Site (state/prov.) } & \multirow[b]{2}{*}{$\begin{array}{l}\text { Lat., } \\
\text { Long. }\end{array}$} & \multicolumn{3}{|c|}{ Prior to experiment (1971-2008) } & \multicolumn{3}{|c|}{ During experiment (2009-2011) } \\
\hline & & $\begin{array}{l}\text { JJA temp. } \\
\left({ }^{\circ} \mathrm{C}\right)\end{array}$ & $\begin{array}{l}\text { JJA PPT } \\
(\mathrm{mm})\end{array}$ & $\begin{array}{l}\text { DJF } T_{\min } \\
\quad\left({ }^{\circ} \mathrm{C}\right)\end{array}$ & $\begin{array}{l}\text { JJA temp. } \\
\left({ }^{\circ} \mathrm{C}\right)\end{array}$ & $\begin{array}{l}\text { JJA PPT } \\
(\mathrm{mm})\end{array}$ & $\begin{array}{l}\text { DJF } T_{\text {min }} \\
\quad\left({ }^{\circ} \mathrm{C}\right)\end{array}$ \\
\hline ALUM (Arkansas) & $\begin{array}{l}34.8^{\circ} \mathrm{N} \\
93.0^{\circ} \mathrm{W}\end{array}$ & $25.90(0.86)$ & $102.60(30.02)$ & $0.68(1.42)$ & $27.34(1.70)$ & $101.06(12.36)$ & $0.49(1.45)$ \\
\hline KOEN (Arkansas) & $\begin{array}{l}36.0^{\circ} \mathrm{N}, \\
93.2^{\circ} \mathrm{W}\end{array}$ & $24.58(0.88)$ & $85.16(22.02)$ & $-2.71(1.73)$ & $25.96(1.76)$ & 75.97 (26.92) & $-2.84(1.74)$ \\
\hline BREA (Missouri) & $\begin{array}{l}38.7^{\circ} \mathrm{N} \\
92.2^{\circ} \mathrm{W}\end{array}$ & $24.45(0.97)$ & $99.94(38.63)$ & $-5.15(1.97)$ & $24.99(1.66)$ & $120.65(28.37)$ & $-5.47(2.12)$ \\
\hline WILD (Iowa) & $\begin{array}{l}41.5^{\circ} \mathrm{N} \\
90.9^{\circ} \mathrm{W}\end{array}$ & $23.00(0.96)$ & $105.66(38.99)$ & $-8.27(2.40)$ & $23.15(1.55)$ & $140.88(56.22)$ & $-8.95(2.51)$ \\
\hline FISH (Iowa) & $\begin{array}{l}43.5^{\circ} \mathrm{N} \\
91.3^{\circ} \mathrm{W}\end{array}$ & $21.45(0.95)$ & $112.93(36.86)$ & $-11.17(2.78)$ & $21.73(1.65)$ & $124.25(57.25)$ & $-11.32(3.15)$ \\
\hline PINE (Minnesota) & $\begin{array}{l}45.2^{\circ} \mathrm{N} \\
92.8^{\circ} \mathrm{W}\end{array}$ & $20.68(1.01)$ & $111.31(30.32)$ & $-13.64(2.81)$ & $20.51(1.40)$ & $118.31(16.51)$ & $-13.97(3.49)$ \\
\hline PIKE (Minnesota) & $\begin{array}{l}47.3^{\circ} \mathrm{N} \\
94.5^{\circ} \mathrm{W}\end{array}$ & $18.72(1.10)$ & $95.15(23.74)$ & $-17.96(3.08)$ & $18.46(1.51)$ & $92.10(31.49)$ & $-17.60(3.78)$ \\
\hline TBAY (Ontario) & $\begin{array}{l}48.3^{\circ} \mathrm{N} \\
89.4^{\circ} \mathrm{W}\end{array}$ & $16.22(0.93)$ & $79.90(20.50)$ & $-18.24(2.67)$ & $16.82(1.75)$ & $74.77(12.08)$ & $-17.27(3.36)$ \\
\hline FORT (Ontario) & $\begin{array}{l}48.8^{\circ} \mathrm{N} \\
93.4^{\circ} \mathrm{W}\end{array}$ & $17.48(1.13)$ & 97.34 (29.91) & $-19.10(3.30)$ & $17.04(1.43)$ & $87.14(35.29)$ & $-20.07(4.47)$ \\
\hline DRYD (Ontario) & $\begin{array}{l}49.9^{\circ} \mathrm{N} \\
92.3^{\circ} \mathrm{W}\end{array}$ & $17.56(1.24)$ & $96.02(23.26)$ & $-19.78(2.76)$ & $17.46(1.43)$ & $88.24(34.72)$ & $-18.23(3.97)$ \\
\hline
\end{tabular}

Notes: Climate data were obtained from the PRISM Climate Group of Oregon State University (for ALUM, KOEN, BREA, WILD, FISH, PINE, and PIKE) and the Canadian National Climate Data and Information Archive (for TBAY, FORT, and DRYD).

plots, and with the exception of the two most southerly sites (where blueberry [Vaccinium spp.] was abundant and regrew vigorously), average basal area of resprouting woody stems was $78 \%$ lower in clip plots than no clip plots. At all but one site, this corresponded to a $75 \%$ to $98 \%$ reduction in biomass removed from clip plots compared to 2009. At the centrally located site where the effect of clipping on regrowth was least strong ( $42 \%$ reduction in biomass), maintenance clipping was done twice a summer, and the difference in seedling growth and survival between clipped and unclipped plots was comparable to other sites. At most sites, light availability within a canopy cover type was generally similar between clipped and unclipped plots. The clipping effect on light was greatest at the three most northern sites, where the understory was dense and the canopy thin: clip gap and shade plots had up to two times more light than their unclipped counterparts. Within clip treatments, however, light levels for gap and shade plots were clearly differentiated at each site: percent light in clip gaps was always higher than in clip shade plots, and likewise for unclipped plots.

\section{Statistical analysis}

We assessed correlations between latitude and three-year averages of multiple climate variables: mean annual temperature (MAT), mean annual precipitation (MAP), summer temperature, summer precipitation, summer moisture availability index (aridity), DecemberFebruary (winter) minimum temperature, and winter precipitation. Climate variables were strongly correlated with latitude and with each other, with the exception of summer precipitation, which was not correlated with either temperature or annual precipitation (Appendix S1: Fig. S3). Models with average summer temperature as the sole climate variable, however, had lower Akaike information criterion (AIC) values than models that included summer precipitation as well. AIC values were lowest in models that used either average summer temperature or summer aridity as the sole climate variable, but the direction of the relationship made biological sense only for temperature. Seedlings grew better with warmer temperatures or with greater aridity, but as aridity is typically considered to be primarily a plant stressor, the most parsimonious explanation is that warmer temperatures drove growth. In this relatively mesic biome, the correlation between aridity and seedling growth arises because both were also correlated with summer temperatures. Because summer temperatures are also correlated with winter minimum temperatures, summer temperature can function as an index of climate stress, and this might be reflected in direct effects on growth and/or indirect effects on competitive ability. Summer temperature is therefore particularly well-suited to address our hypotheses, and we use this climate variable in models throughout the paper. Additionally, the functional relationship between summer temperature and seedling growth yields a more meaningful interpretation of range-limiting dynamics than an analysis based on latitude.

Given our hypotheses (Fig. 1) of nonlinear, and perhaps nonlinearizable, relationships of growth or survival with summer temperature, we anticipated needing to employ a nonlinear model to best fit the observed responses and test for differences in responses among the three populations. 
A comparison of AIC values for linear and nonlinear (squared polynomial) models, however, indicated that for all response variables, linear mixed effects models better fit the data, confirming a visual inspection of the data that the response to summer temperature was predominantly linear. As our experiment was factorial by design, we therefore used a full factorial standard least squares REML model to evaluate the effects of predictors on growth. Net seedling growth over the experiment, reflected in ecological metrics such as final seedling height, diameter, and dry mass, was used rather than relative growth rate (RGR) due to the three-year interval between planting and harvest. Seedling biomass provided an integrated indicator of seedlings' growth and dieback over the course of the experiment, while seedling height may predict future success in reaching the canopy (Cole and Lorimer 2005). Log-transformed final seedling mass, height, diameter, and total stem extension were response variables in cumulative growth models, while log-transformed annual height, stem extension, and basal diameter were response variables in annual growth models. When we compared the full factorial model to others that removed nonsignificant interactions, model performance generally improved somewhat but did not materially alter our reported results in term of significant main effects and interactions.

All analyses included seedling size, either initial size (for cumulative growth models) or prior year seedling size (for annual models), as a covariate to account for and standardize the effects of initial or prior size on growth response variables over the course of the experiment. Preliminary analyses of seedling final height, diameter, cumulative stem extension, and mass that included initial height, population, and their interaction as predictors show that, despite the wide range in initial seedling size (Appendix S1: Fig. S2), populations share a similar relationship between initial and final size (e.g., Appendix S1: Fig. S4). Initial size was always a very strong predictor of final size, and there was weak to no evidence that populations differed in the slope of final size metrics vs. initial size $(P>0.05, F$ ratios $\leq 3)$ but very strong evidence of the overall influence of initial size $(P<0.0001, F$ ratios 76-149). When we used adjusted least square means of each population, derived from the analyses of covariance, to systematically adjust values to account for initial size differences and eliminate those effects, population differences in final diameter, stem extension, and mass were highly significant $(P<0.0001, F$ ratios $45-67)$ while final height did not significantly differ among populations. This is consistent with our full analyses (Table 4) and indicates that the initial size covariate adequately adjusts for initial size differences among populations.

In all models, plot was nested within site and both site and plot were entered as random effects in the model, an approach that addressed site-specific variation in seedling performance unrelated to the variables of interest as well as variation among the sites in understory vegetation density. Preliminary analyses indicated that continuous variables quantifying density of understory vegetation in clipped and unclipped plots, as well as differences in light

TABLE 4. The effects of population (northern, central, and southern origin), clip treatment (clipped or unclipped aboveground vegetation), canopy cover type (shaded understory or canopy gaps), and temperature (10 transplant sites spanning a $9.8^{\circ} \mathrm{C}$ difference in average summer temperature) on survival (nominal logistic model) and log-transformed seedling mass, diameter, height, and cumulative stem extension (linear mixed effects models) over a three-year period.

\begin{tabular}{|c|c|c|c|c|c|c|c|c|c|}
\hline \multirow[b]{2}{*}{ Model factor } & \multirow{2}{*}{$\frac{\text { Survival }}{\chi^{2}}$} & \multicolumn{2}{|c|}{ Mass } & \multicolumn{2}{|c|}{ Diameter } & \multicolumn{2}{|c|}{ Height } & \multicolumn{2}{|c|}{ Extension } \\
\hline & & $F$ & $\mathrm{df}$ & $F$ & df & $F$ & df & $F$ & df \\
\hline Population & $56.2 * * * *$ & $159.3^{* * * *}$ & 2,574 & $15.0 * * * *$ & 2626 & & & $129.6^{* * * *}$ & 2,618 \\
\hline Clip treatment & $11.8 * * *$ & $18.5^{* * * *}$ & 1,385 & $11.0^{* * *}$ & 1406 & & & $4.2^{*}$ & 1,401 \\
\hline Canopy cover type & $35.4 * * * *$ & $45.7 * * * *$ & 1,386 & $25.3 * * * *$ & 1408 & $36.3 * * * *$ & 1,351 & $31.0 * * * *$ & 1,400 \\
\hline Temperature & $236.6^{* * * *}$ & & & $4.9^{\dagger}$ & 1,9 & & & & \\
\hline Pop $\times$ Clip & & $3.2 *$ & 2,523 & & & & & & \\
\hline Pop $\times$ Canopy & & & & & & & & & \\
\hline Pop $\times$ Temp & $52.6 * * * *$ & $2.8^{\dagger}$ & 2,557 & & & $8.2 * * *$ & 2,568 & $4.4^{*}$ & 2,594 \\
\hline Clip $\times$ Canopy & & & & & & $2.9^{\dagger}$ & 1,330 & & \\
\hline Clip $\times$ Temp & & & & & & & & & \\
\hline Canopy $\times$ Temp & $5.6^{*}$ & & & & & $3.7^{\dagger}$ & 1,426 & & \\
\hline Pop $\times$ Clip $\times$ Canopy & & & & $3.5^{*}$ & 2,540 & & & & \\
\hline Pop $\times$ Clip $\times$ Temp & & $3.0^{*}$ & 2,560 & & & & & & \\
\hline $\begin{array}{l}\text { Pop } \times \text { Canopy } \times \text { Temp } \\
\text { Clip } \times \text { Canopy } \times \text { Temp }\end{array}$ & & & & & & & & & \\
\hline $\begin{array}{l}\text { Clip x Canopy } \times \text { Temp } \\
\text { Initial size covariate }\end{array}$ & & & & & & $2.8^{\dagger}$ & 1,388 & & \\
\hline Initial size covariate & & $176.8^{* * * *}$ & 1,684 & $467.9^{* * * *}$ & 1,728 & $151.9^{* * * *}$ & 1,740 & $86.9 * * * *$ & 1,737 \\
\hline
\end{tabular}

Notes: In the mixed-effects models, both site and plot (nested within site) were entered as random effects to account for sitespecific variation in seedling performance unrelated to temperature. Seedling mass, diameter, and height measurements were made at the end of the experiment; summer temperature (June-August) data, obtained from the PRISM Climate Group of Oregon State University and the Canadian National Climate Data and Information Archive, was averaged over the three years of the experiment. Log-transformed initial height was used as a covariate for all response variables but final diameter, where log-transformed initial diameter was used instead. Survival, $\chi^{2}=410.01, N=1293$; mass, $R^{2}=0.783, N=714$; diameter, $R^{2}=0.795, N=772 ;$ height, $R^{2}=$ $0.647, N=770$; extension, $R^{2}=0.705, N=770$.

$\dagger P<0.1, * P<0.05, * * P<0.01, * * * P<0.001, * * * * P<0.0001$. 
levels between the canopy cover types, yielded results similar to models with categorical variables. Three-year average summer temperature was used as the climate variable for models with a cumulative growth response, while annual models used summer temperature data from that year. A proportional hazards model to analyze survival over the 35 months of the experiment was run with the full data set, and a nominal logistic model to analyze final survival was run for nine sites; one site was excluded because it had to be harvested early. Data were analyzed with JMP Pro 9.0 statistical software (SAS Institute, Cary, North Carolina, USA).

\section{RESULTS}

We found significant differences in seedling survival, growth, and phenology across the latitude and climate gradient encompassed by this experiment. The effect of summer temperature on seedling growth and survival varied by population and, to a lesser extent, canopy light availability and the presence of understory neighbors. Though results provided partial support for our three specific hypotheses, performance at warmer sites and beyond both range margins was unexpectedly high, and the results did not support our over-arching hypothesis that climate and competition were the primary rangelimiting factors at the seedling stage.

\section{Survival response}

In the full nominal logistic model for final percent survival over the three years of the experiment, all main factors (population, clip treatment, canopy cover type, and the three-year average of mean summer temperature) were highly significant, and there were also significant two-way interactions involving summer temperature (Table 4). Averaged across sites, survival was highest for northern population seedlings, while seedlings from the central population had the lowest survival. As hypothesized, each population's survival tended to increase with mean summer temperature, but in contrast to our hypothesis ( $\mathrm{H} 1)$, none of the populations showed any evidence of a plateau or decline in survival beyond their region of origin, and highest overall survival occurred at warm southern sites. There was a significant interaction between population and summer temperature $\left(\chi^{2}=51.7\right.$, $\mathrm{df}=2, P<0.0001)$ : the positive survival response to temperature was much stronger in the southern and central populations than the northern population (Fig. 3a). Seedling survival at cold northern sites was 2- to 10-fold higher in the northern population than in the central or southern populations, while at warm southern sites, seedling survival was $4 \%$ to $19 \%$ higher in the southern population than in central or northern populations (Fig. 3a). Thus, although most of the population-specific predictions of the overall hypothesis (H1) were not supported, the prediction about differences among populations was upheld.

On average, a higher proportion of seedlings survived in clipped plots $(55 \%)$ than in unclipped plots $(47 \%)$ and in canopy gaps $(58 \%)$ than in shade plots $(44 \%)$. As hypothesized (H2), however, seedling survival in gaps was no higher than in canopy shade at the southernmost sites (Fig. 4a), leading to a significant interaction between summer temperature and canopy cover type in the nominal logistic model $\left(\chi^{2}=5.3\right.$, df $\left.=1, P<0.05\right)$.
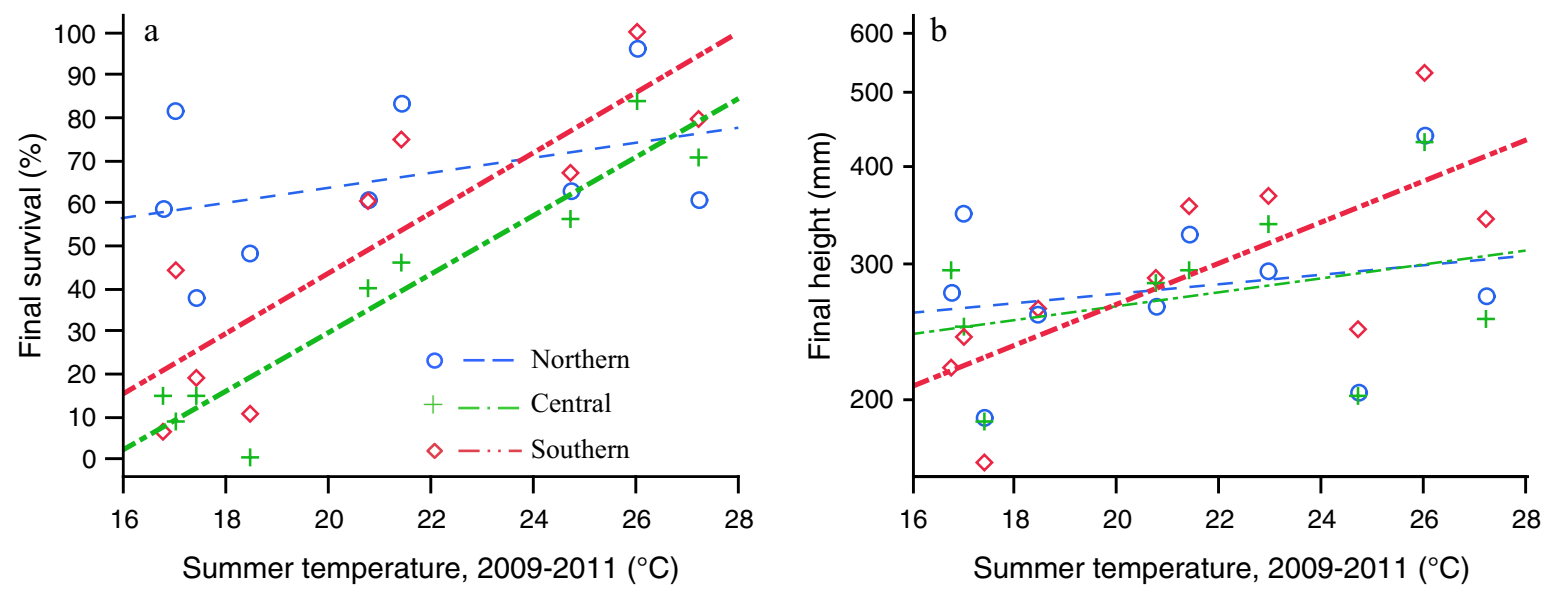

FIG. 3. (a) Final percent survival and (b) adjusted mean final height of seedlings across sites. Both seedling survival and final height are positively correlated with mean summer temperatures, increasing at warmer (low latitude) sites. At northern sites, the northern population out-survived (but did not substantially outgrow) the southern population, while at southern sites, the southern population both outgrew and out-survived the northern population, though differences in survival were less marked. The central population had growth patterns similar to the northern population and survival patterns similar to the southern population. Other growth metrics (not shown) such as total stem extension, final stem diameter, and final seedling mass showed similar patterns to height, but the southern population had higher growth than the northern population even at the coldest sites. Heavy trend lines indicate relationships with slopes significantly different from zero: percent survival for the central $(P=0.0001)$ and southern $(P<0.01)$ populations and average height for the southern population $(P<0.05)$. 

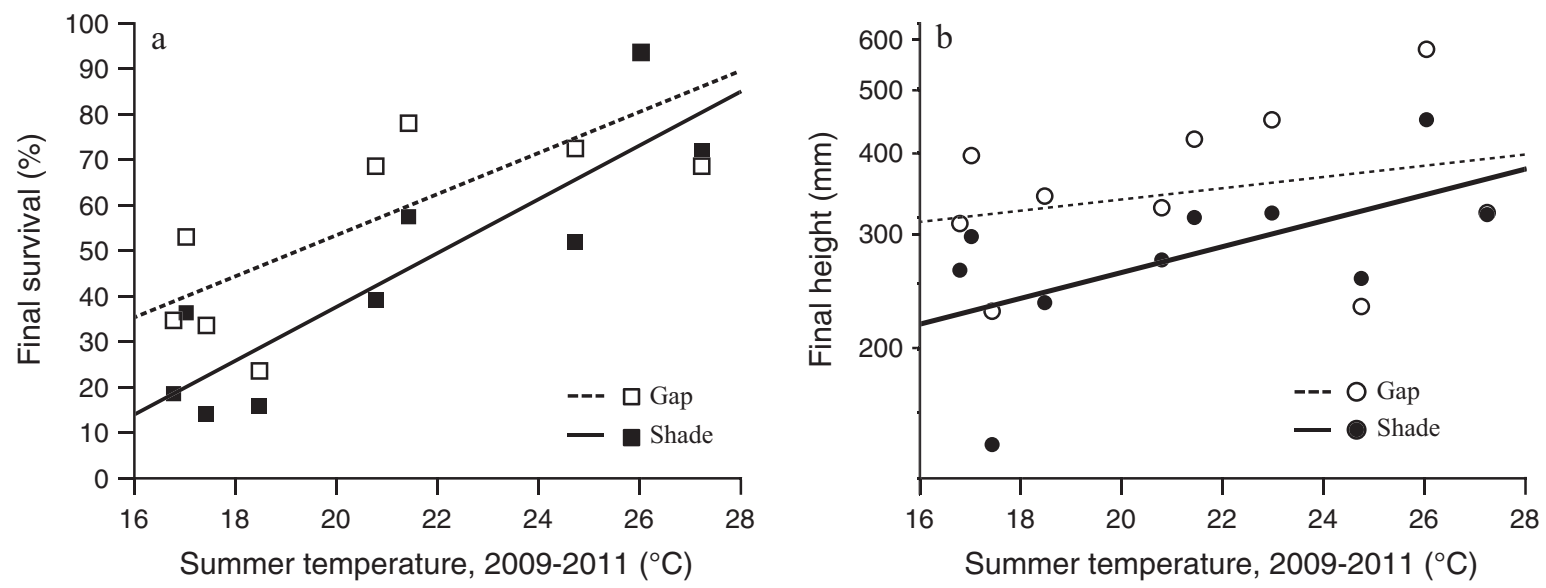

FIG. 4. (a) Final percent survival and (b) final height of seedlings across sites, separated by canopy cover type. Both survival and net growth were higher on average in gaps than in shade plots, and differences in performance between canopy cover types were greatest at northern (colder) sites. Heavy trend lines indicate relationships with slopes significantly different from zero: percent survival in gaps $(P<0.05)$ and shade $(P<0.01)$ and average final height in shade $(P=0.067)$. Values shown are means.

Treatment effects on survival also varied with time: all main effects in a full proportional hazards model were significant, and the difference in cumulative survival between treatments tended to increase over time (data not shown). There was also a significant interaction between population and mean summer temperature in this model: for central and southern populations, survival differences across the temperature gradient were most pronounced in the first year, while for the northern population these differences continued to grow larger over time (Fig. 5).

Population-specific differences in mortality were apparent within the first year of the experiment and were especially pronounced at cold northern sites (Fig. 5). Contrasting patterns of seasonal mortality were also evident between northern and southern populations in the timing and proportion of seedlings that died from one time step to the next (Appendix S1: Fig. S5): summer mortality, measured as the proportion of seedlings that died between spring and summer visits, was generally low across the range for both northern and southern populations, while winter seedling mortality (the proportion that died between the summer visit and the following spring) of the southern population at northern sites was twofold to fourfold higher than for the northern population in the first year (Fig. 6); the central population (not shown) showed seasonal patterns of survival roughly similar to the southern population. This is consistent with our hypothesis that populations would show evidence of local adaptation and decreasing survival with distance of climate transfer, though the northern population did not show a similar decline in survival at southern sites.

\section{Growth response}

Cumulative seedling growth was analyzed with a variety of response variables: final seedling height, mass, diameter, and total stem extension. Of these, seedling a) Northern population

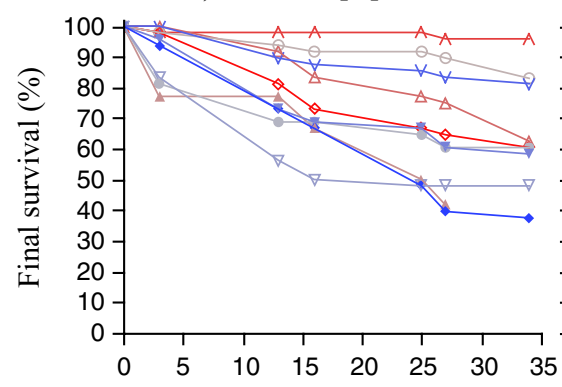

b) Central population

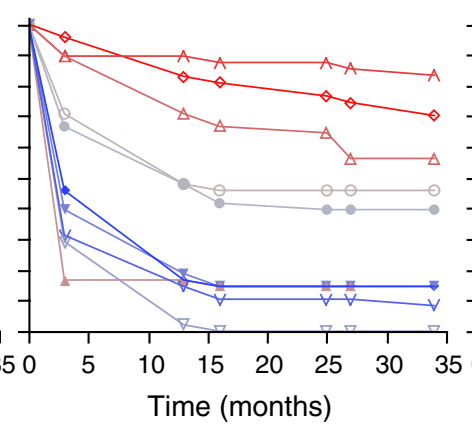

c) Southern population

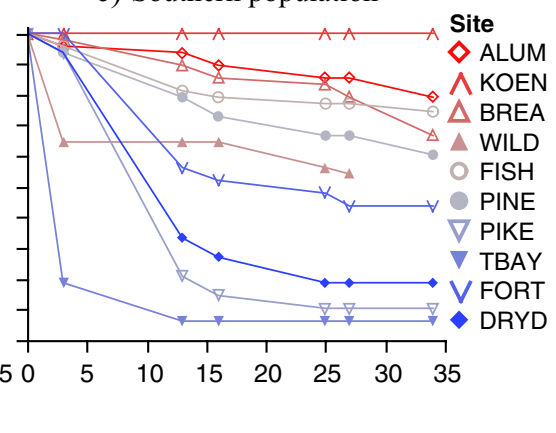

FIG. 5. Percent survival over time for the (a) northern, (b) central, and (c) southern populations, separated by site. Each site was represented by a unique symbol and is listed from southern to northern latitudes (top to bottom). One centrally located site (in Muscatine, Iowa) was harvested early, so no data are available for the last time step. Survival declined over time at most sites: mortality at southern sites was relatively constant across years, while at northern sites, highest mortality occurred in the first year. Sites are identified in Table 1. 


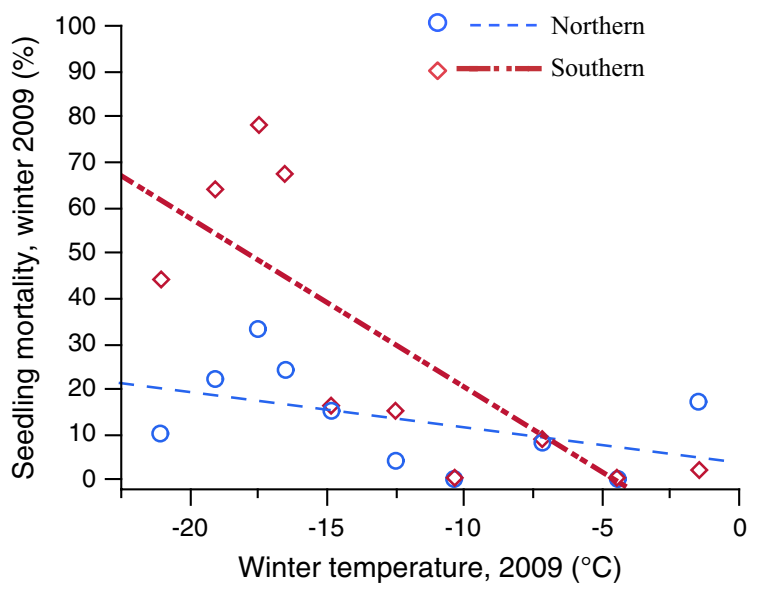

FIG. 6. In the first winter (2009-2010), average overwinter seedling mortality was lower at sites with colder winter (December-February) minimum temperatures for the southern, but not the northern, population. Northern-origin seedlings did not exhibit a significant relationship between winter minimum temperatures and mortality, but southern-origin seedlings had significantly higher mortality at northern sites $(P<0.01$, heavy trend line). Mortality differences between populations and across sites showed a similar, but nonsignificant, pattern in 2010; the lack of significance is likely a result of the southern population's high mortality at northern sites over the first winter. Temperature values are means.

height is most directly proximate to a young tree's ability to reach the canopy and become a reproductive individual. We therefore focus first on final seedling height, then address how other growth metrics differed.

In all three populations, height growth was higher at warmer sites, and thus none of the populations showed the hypothesized plateau or decline in growth response at the highest temperatures (Fig. 3b), refuting $\mathrm{H} 1$ for the warm end of the climate transect. However, populations differed in the strength of their response (Fig. 3b); in a full linear

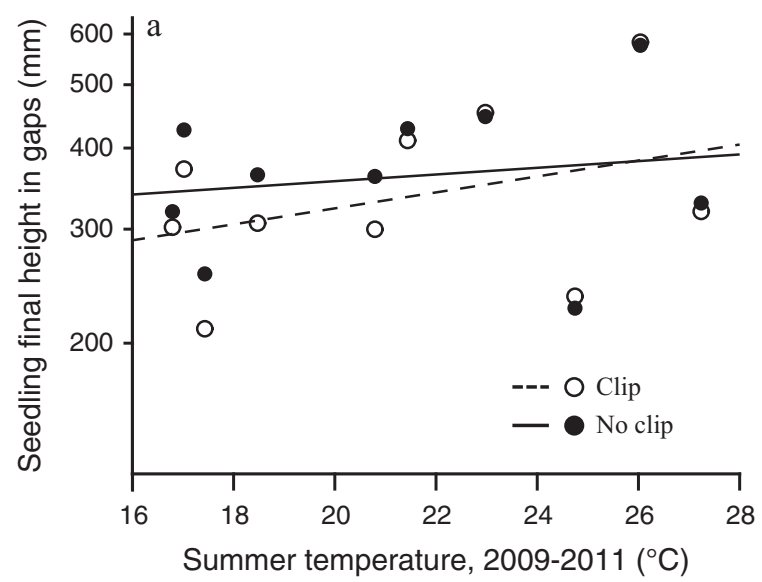

mixed effects model for final seedling height, there was a significant population $\times$ mean summer temperature interaction $\left(F_{2,568}=8.15, P<0.001\right.$; Table 4$)$. Only the southern population seedlings showed a strong positive height response to increasing mean summer temperature; they outperformed the other populations at southern but not at northern sites (Fig. 3b). Thus, as with survival, although several of the population-specific growth predictions of the overall hypothesis (H1) were not supported, the prediction about differences among populations was upheld.

Understory neighbor density did not have a significant main effect on height growth, in contrast to our hypothesis (H2). Canopy cover type, on the other hand, did influence height growth (H3), as seedlings grew taller on average in gap environments (Table 4). Furthermore, the hypothesized biogeographic variation in the impact of understory neighbors on maple growth (H2) was supported, though only in canopy gaps: in the colder north, seedlings in gaps were taller when understory neighbors were present (Fig. 7a), and this effect disappeared in warmer climates. Seedlings in canopy shade, on the other hand, did not significantly differ in height between clipping treatments or in their response to clipping across the climate gradient (Fig. 7b). Canopy cover type was marginally significant both as a main effect and through interactions with clip treatment $\left(F_{1,330}=2.91, P<0.1\right)$, mean summer temperature $\left(F_{1,426}=3.67, P<0.1\right)$, and a three-way clip treatment $\times$ canopy cover type $\times$ mean summer temperature interaction $\left(F_{1,388}=2.84, P<0.1\right)$ (Table 4$)$. Across sites, final seedling height was on average $27 \%$ greater in gap than in shade plots, but as predicted (H3), this was driven by performance at colder sites, where seedlings were $37 \%$ taller on average in gaps than in shade plots; at warmer sites, in contrast, there was little difference in height among the clip treatments and canopy cover types (Fig. 4b). Moreover, the clipping treatment reduced the difference across sites in height performance in gaps

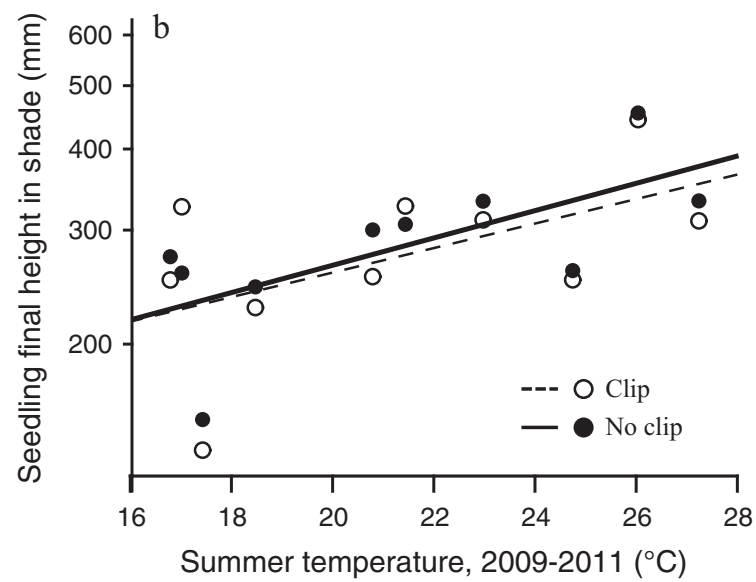

FIG. 7. Effects of clipping on seedling height growth in (a) gap and (b) shade plots. Seedling height growth in gaps was relatively constant across sites, but the effect of clipping was not, reducing seedling height at northern but not southern sites. In shade plots, seedlings had lower height growth overall but especially at northern sites. The clipping treatment did not substantially reduce height growth in shade plots. Temperature values are means. 


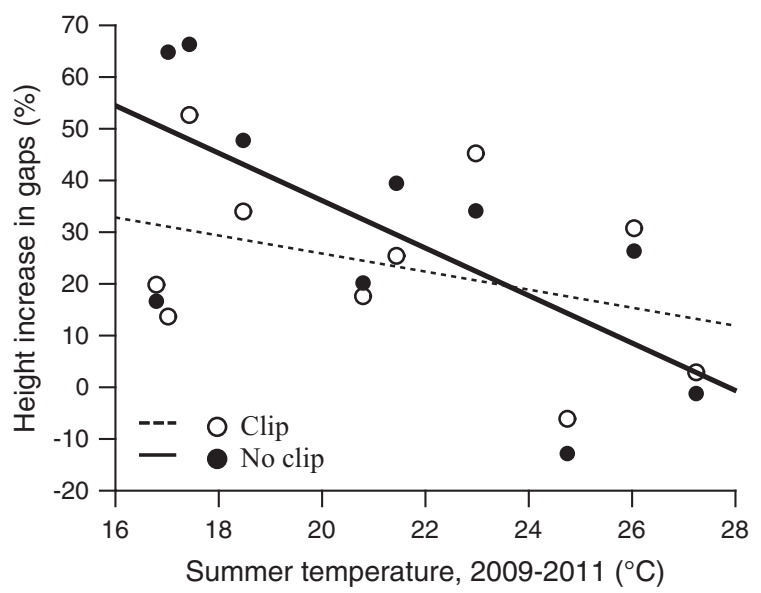

FIG. 8. Site-specific effects of the clipping treatment on the "gap benefit," or degree to which seedling height growth was greater in gaps relative to shade. Canopy type's effect on seedling height was not constant across sites: at northern sites, gap-grown seedlings were much taller relative to shade-grown seedlings, while at southern sites this height difference was much smaller. The clipping treatment evened the difference in height response to light environment across sites: clipping at northern sites reduced the gap benefit on seedling height at northern sites and enhanced it at southern sites. This is reflected in the trend lines: the gap benefit declined significantly with increasing summer temperature $(P<0.05$; heavy line), while the slope of the clipping treatment best-fit line across sites is not significantly different from zero. Values shown are means.

relative to shade: at cold northern sites, clipping reduced the height benefit of gaps by $19 \%$ on average, while at warmer southern sites clipping enhanced the "gap benefit" by $7 \%$ (Fig. 8).

Final seedling height for all three populations was, on average, positively correlated with final survival across temperature, clip treatments, and canopy cover types (Fig. 9). For the southern population, this reflects both higher survival and higher growth at southern vs. northern sites. Additionally, height and survival were linked via site-specific differences in overall performance, though the northern population had a more muted response to the temperature gradient.

Our hypotheses were supported across growth metrics, and results for the main effects were largely consistent among all growth models (Table 4). In each of the full linear mixed effects models for growth, canopy cover type was a highly significant main effect: seedlings were not only taller in gaps but also had greater mass, basal diameter, and total stem extension. For all growth metrics except final seedling height, sugar maple performance differed significantly among the populations: after taking initial differences in size into account, southern seedlings had greater mass, basal diameter, and total stem extension than seedlings from northern or central populations, which were more similar.

As a main effect, the clipping treatment was nonsignificant for seedling height, but it had a highly significant effect on seedling mass and basal diameter and a moderately significant effect on stem extension, all of which increased in clip plots as hypothesized. As only one population had a strong positive response to summer temperature, this predictor was largely nonsignificant as a main effect in growth models, though it had a marginally significant effect on seedling basal diameter, which increased with warmer temperatures.

The population $\times$ mean summer temperature interaction was the only one significant across most growth models, though the degree of effect varied. In addition to seedling height, the interaction was moderately significant for stem extension $\left(F_{2,594}=4.45, P<0.05\right)$ and seedling mass $\left(F_{2,557}=2.79, P<0.1\right)$ : consistent with the results for height, the southern population also had greater mass and more stem extension, especially at warmer sites. The interaction was nonsignificant, however, for basal diameter.

The clipping treatment was associated with statistically significant differences in final seedling mass across populations and temperature (population $\times$ clip treatment $\left[F_{2,523}=3.22, P<0.05\right]$, population $\times$ clip treatment $\times$ mean summer temperature $\left[F_{2,560}=3.05, P<0.05\right]$ ), partially supporting H2 (Fig. 10). Though not hypothesized, clipping response varied among populations: reducing understory neighbors increased seedling mass by $17 \%$ in the northern population and $16 \%$ in the central population, but only increased seedling mass by $3 \%$ in the southern population. This is a case, however, where initial size differences may have influenced results, as larger individuals early in the experiment would have experienced different degree of shading from the samesized neighbors. Across the temperature gradient, both warmer temperatures and the clip treatment increased seedling mass of the northern and central population, though for the central population, the positive effect of

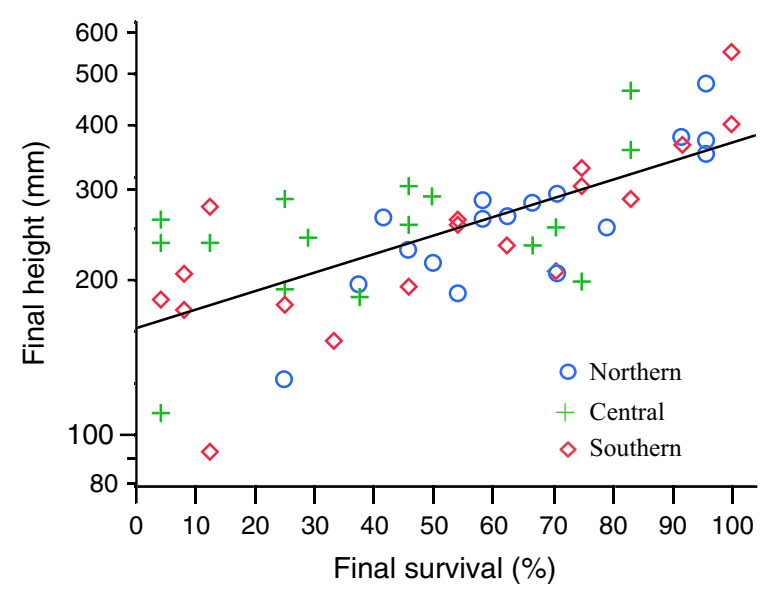

FIG. 9. The relationship between adjusted mean final seedling height and final percent survival for the northern, central, and southern populations. Final height and survival are correlated $\left(R^{2}=0.50\right)$; in both canopy cover types, conditions that were favorable for survival were also favorable for growth $(P<0.0001)$. One centrally located site (in Muscatine, Iowa) was harvested early and thus is not included. 


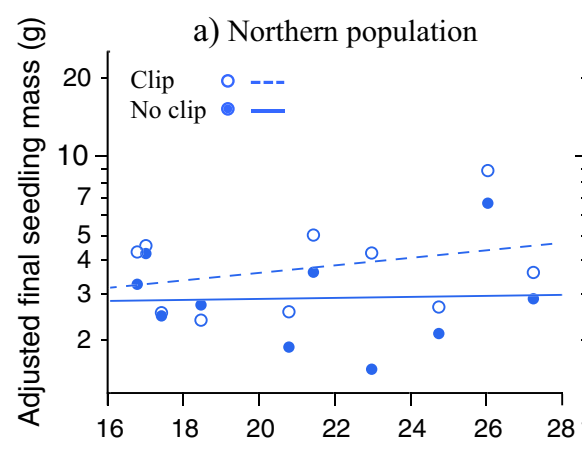

b) Central population

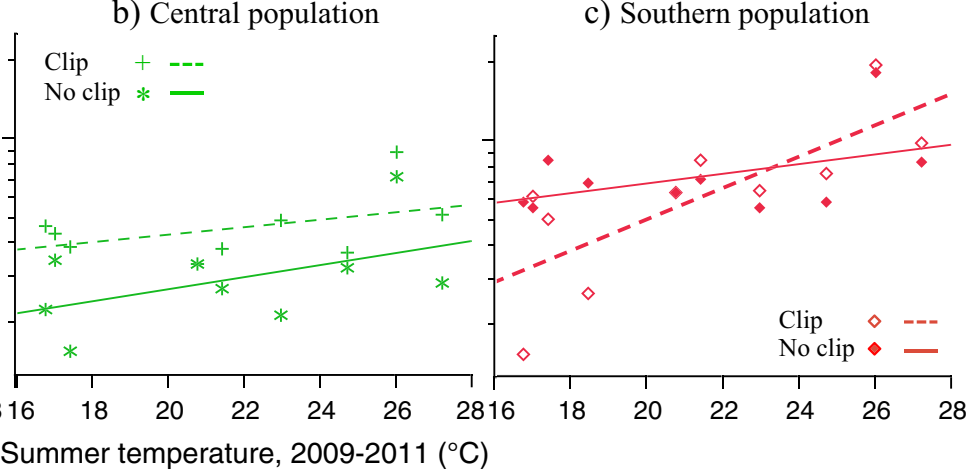

FIG. 10. Adjusted final seedling mass across sites for the northern, central, and southern populations, separated by clip treatment. Northern and central populations had higher average mass in clip plots, while the southern seedling had higher mass in unclipped plots at northern sites and in clipped plots at southern sites. Trend line slopes are not significantly different from zero with the exception of the clipping treatment effect across sites for the southern population $(P<0.05)$. Temperature values are means.

clipping was greatest at colder sites. Seedling mass also showed the hypothesized (H2) switch from a negative to positive effect of clipping in the southern population: its seedling mass was reduced by clipping at colder sites and enhanced at warmer sites.

\section{Annual patterns in growth and survival}

Seedling responses to experimental conditions, expressed in final percent survival and cumulative growth variables, could reflect either a consistent response across the three years of the experiment or a response that varied in strength or direction across years. To address this, we analyzed annual survival and growth responses, using the same basic model but substituting annual summer mean temperatures for the three-year average and the previous years' size as a covariate; we found patterns in survival, and to a lesser extent growth, did in fact change over the years of the experiment.

Overall seedling mortality and the difference in mortality between populations were both greatest in the first year, when mortality rates were $19 \%$ in the northern population, $38 \%$ in the southern population, and $57 \%$ in the central population; the difference between populations' survival declined in successive years (Appendix S1: Table $\mathrm{S} 1$ ). The southern three sites had twice the survival of the northernmost sites in the first year, and while the pattern of survival across sites was similar in the following years, the effect of mean summer temperature on survival was significant in the first two years but not the third year of the experiment. Seedling survival was higher overall in gaps and in clipped plots, and this effect increased over time: in the first year, survival was $10 \%$ higher in gaps than in shade and 3\% higher in clipped plots than unclipped plots, while by the final year, survival was $14 \%$ higher in gaps and $8 \%$ higher in clip plots.

Seedling growth response was largely consistent over the experiment, but response to clipping and temperature differed by year (Appendix S1: Table S2). In the first growing season after planting, seedling height was $4 \%$ lower in the clip treatment, and while clipping increased final basal diameter and stem extension by $4 \%$ and $7 \%$, respectively, over the course of the experiment, these effects did not become significant until the second or third year of the experiment, respectively. Mean summer temperature had a significant positive effect on seedling growth in two of the three years; the effect was nonsignificant in the hot, dry summer of 2011. While the clipping treatment significantly reduced the gap benefit, or difference in final height between gap- and shade-grown seedlings, at cooler sites (see Fig. 8), this effect was not significant for annual height growth.

The population $\times$ summer temperature interaction for height growth noted across the three years of the study was also significant for annual height and stem extension in both 2009 and 2010 (but not 2011) when each year was analyzed independently. An interaction between summer temperature and canopy cover type, significant for final seedling height, was significant only in 2010, when both height and extension were lower in shade plots, especially at cold sites. The three-way interaction between population, clip treatment, and summer temperature was significant only for final seedling mass and not for any annual growth variable.

In certain years (2009 and 2010 for stem extension, 2011 for height), populations also differed in their response to canopy cover type across sites. Southern and central population seedlings growing in shade plots responded to warmer temperatures with increased extension or height, while in gap plots, extension or height in these populations remained relatively constant across sites. The northern population, on the other hand, had a weak, nonsignificant response of stem extension to temperature and no change in the relative performance of seedlings in gap and shade plots across sites. Though this interaction was not significant in the analysis of cumulative stem extension or final height, it is consistent with previously discussed two-way interactions in final growth models (e.g., population $\times$ temperature, temperature $\times$ canopy cover type). 


\section{Phenology response}

Phenology data on spring leaf expansion and fall leaf senescence, collected in 2011 from a cold-climate northern site (Cass Lake, Minnesota) and a warm-climate southern site (Jasper, Arkansas), revealed differences in phenology response between populations and sites (Fig. 11). Though volunteers missed the critical spring leaf-out window at the Minnesota site and the beginning of senescence at the Arkansas site, the incomplete results are suggestive of differences in populations' response to seasonal cues as well as growing season length across sites. The northern population leafed out faster in spring and had full-sized leaves earlier than the southern population, while in the fall, the northern population senesced earlier than the southern population. At the southern site, the northern population's growing season (from completion of leaf-out to estimated initiation of senescence) was about six weeks longer than at the northern site, mostly due to earlier leaf-out in spring. The southern population's growing season at the southern site was even longer, but as only $57 \%$ of seedlings from the southern population had

a) Southern site (Jasper, Arkansas)

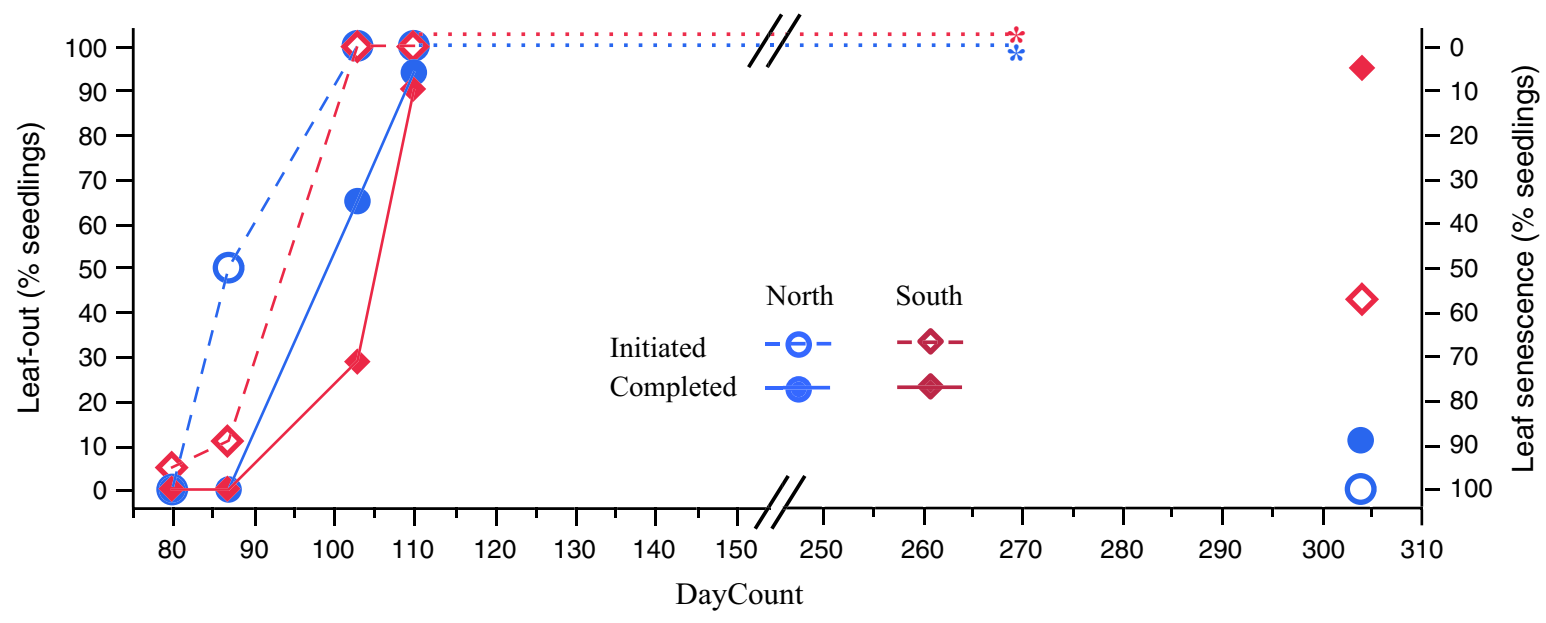

b) Northern site (Cass Lake, Minnesota)

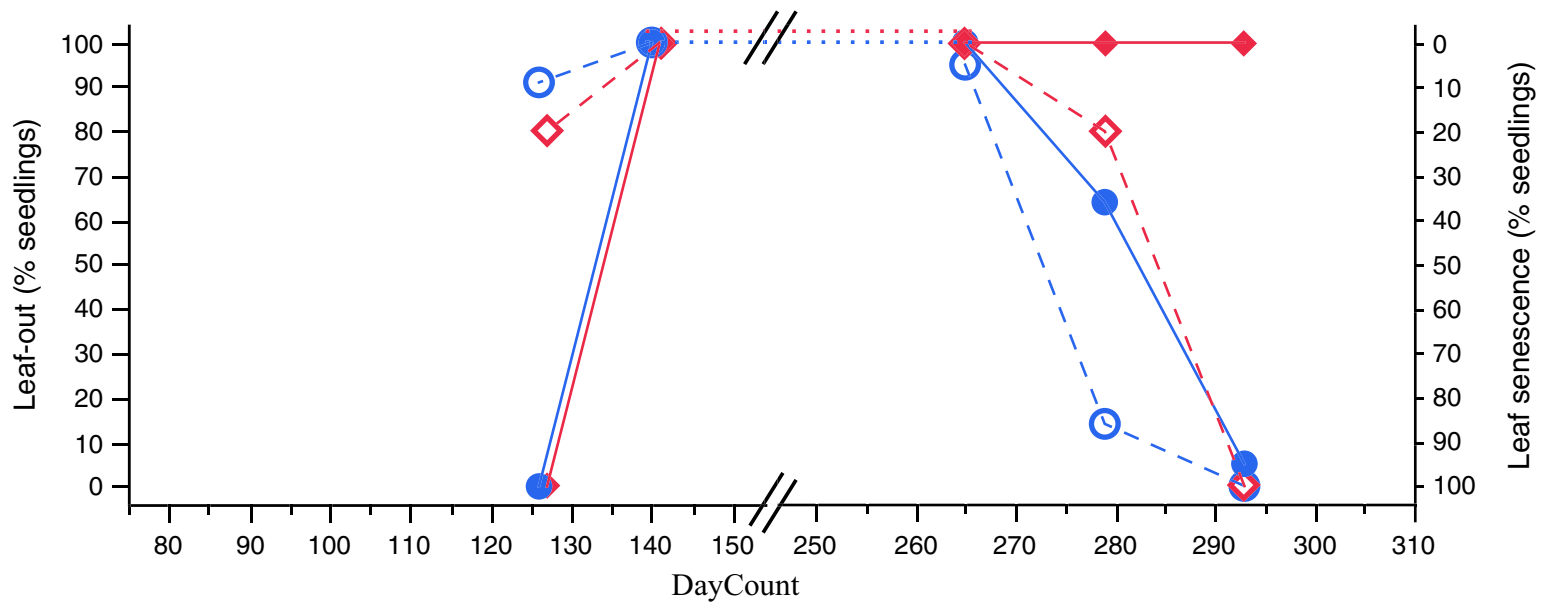

FIG. 11. Phenology data for northern and southern seedlings from (a) a southern site (Jasper, Arkansas) just beyond the continuous distribution of sugar maple and (b) a northern site (Cass Lake, Minnesota) near the northern range margin, illustrating the percentage of seedlings that had initiated and completed leaf-out in spring and leaf senescence in fall. Data on leaf-out at the Minnesota site and senescence at the Arkansas site are incomplete, as volunteers missed visits during these key times; at the southern site, we believe seedlings were in full leaf at least until the date marked by asterisks, but we do not have a date at which the populations initiated senescence. Spring leaf-out initiated with bud elongation and was complete when most leaves on an individual were extended and full size; fall senescence initiated with changes in leaf color and was complete following full leaf abscission. At both sites, the northern population leafed out slightly before the southern population, but the southern population retained green leaves in the fall well after the northern population had senesced and consequently had a longer growing season, especially at the southern site. The date of each visit (DayCount) is given in number of days from 1 January. Phenology data is based on a subset of seedlings at each site: at the southern site, $N=20$ northern and 19 southern seedlings, and at the northern site, where southern seedlings survived poorly, $N=22$ northern and 5 southern seedlings. 
initiated leaf senescence when surveyed, the full length of its growing season is unknown. At the northern site, the southern population kept its leaves at least two weeks longer than the northern population, though conditions were likely no longer favorable for growth. At another northern site, snow-covered southern seedlings with green leaves were observed in mid-November, suggesting full senescence might not have been achieved by that population at northern sites prior to winter onset.

\section{Discussion}

While a species' distribution broadly maps the abiotic conditions of its fundamental niche, both models and experimental work suggest that in certain cases, a species' range reflects a realized niche further defined, and usually narrowed, by biotic interactions (Bullock et al. 2000, Cleavitt 2004, Araújo and Luoto 2007, Wisz et al. 2013, Bulgarella et al. 2014). As rapidly changing climate causes abiotic niche conditions to shift geographically, this may lead not only to a disconnect between a species' fundamental niche and its distribution but also cascading effects from changing species distributions and novel interactions (Wisz et al. 2013). Additionally, responses to climate change are likely to differ across the range as a result of intraspecific genetic variation, and examining climatically distinct provenances under contrasting growing conditions may provide insight into potential future climate response across the range and at range margins(Kreyling etal.2014, Lu et al. 2014). Complicating efforts to understand species' potential distribution shifts is the lack of beyond-range transplant studies that examine potential biotic as well as abiotic range-limiting factors under natural conditions and for multiple populations (Hargreaves et al. 2014). This experiment, designed to address these gaps, showed populationspecific responses at northern and southern range margins that emphasize the importance of both broad climate tolerance and local adaptation in conjunction with biotic interactions.

\section{Range-limiting factors at the northern margin}

The strong correspondence between species distributions and climatic thresholds, particularly at high latitudes and altitudes, has been well documented in the literature (Salisbury 1926, Grace 1987, Woodward 1987, Randin et al. 2013). Beyond-range transplant experiments are one of the best ways to detect the limiting effect of climate (Hargreaves et al. 2014), but despite transplanting seedlings several hundred kilometers north of the range boundary, we found only very modest declines in either survival or growth for the northern population. Toward the species' northern margin, seedlings with origins from central and southern portions of the range had marked declines in survival and (for the southern population) in growth, suggesting climate limitation among these populations. Though the northern population's highest survival and growth did not occur at northern sites, there was no statistical difference in its growth and survival across the range and beyond range margins. Moreover, its superior performance relative to the southern population (for growth) and both central and southern populations (for survival) suggest it may be better adapted to a northern climate. Successful sugar maple regeneration was also noted in a stand where summers were cooler than either of the beyond-range transplant sites (R. Putnam, personal observation).

The relatively high survival rate of sugar maple seedlings beyond the northern range margin, coupled with strong recruitment near the northern range edge, raises the possibility that the current distribution of sugar maple at the northern margin does not reflect the climate tolerance of the species, either due to dispersal limitation (e.g., Marsico and Hellman 2009, Samis and Eckert 2009), recent climate warming (e.g., Doak and Morris 2010), or both (e.g., Engler et al. 2009). Northward shifts in the distribution of sugar maple saplings have been noted in Quebec over the past 30 years, but the very low observed migration rate of $0.4 \mathrm{~km} / \mathrm{yr}$ are well short of the estimated dispersal rates necessary to match climate change (Périé et al. 2014), which suggests the rate at which sugar maple shifts its distribution in response to changes in climate is likely to be dispersal-limited (Boisvert-Marsh et al. 2014). Seed predation by small mammals, which has the potential to indirectly limit dispersal, has also been posited as a potential constraint at northern range margins (Kellman 2004, Brown and Vellend 2014).

As elsewhere, the northern range limit of sugar maple has experienced warmer temperatures in recent decades, especially in winter (data not shown), but during this study, average summer and winter temperatures at the range margin either approximated or were lower than 20th-century averages, with the exception of the final winter, which was much warmer than average (Appendix S1: Table S3). Sites beyond the northern range margin showed similar summer and winter temperature patterns over the three years of the study (Appendix S1: Fig. S1a, c), which suggests that the conditions under which seedlings survived and grew during the experiment were in line with the 20th-century climate conditions under which sugar maple trees at the cold northern range limit established and matured. Rare climate events can have a significant effect on plant distributions (Giesecke et al. 2010), however, and occasional climate extremes could play a role in limiting sugar maple's northern range boundary.

Though direct effects of rare climate events on sugar maple survival cannot be excluded as a possible rangelimiting factor, high survival of sugar maple seedlings beyond the northern range margin, also noted in other beyond-range transplant studies of the species (Kellman 2004, Brown and Vellend 2014), suggests the possibility that the northern extent of the range could be constrained at least in part by biotic factors. Negative plant-soil feedbacks have been noted for sugar maple near the northern 
range margin: seedlings experimentally grown in low light had lower survival in conspecific than in heterospecific soils (McCarthy-Neumann and Ibáñez 2012), and beyond-range survival might represent a release from soil pathogens that have accumulated in the soils of sugar maples' native range.

Sugar maple distribution could also be limited by the indirect effects of climate on competitors' metabolism and growth (e.g., Woodward and Pigott 1975); it has been suggested that sugar maple may have historically been outcompeted at its northern range margin by fastergrowing boreal species but that these interactions may shift with changing climate (Fisichelli et al. 2012). Opposite responses of growth and survival to experimental climate change of maple vs. boreal species (e.g., Reich et al. 2015) also suggest that continued climate change could enhance maple capacity to compete at and beyond its current northern limit. The northern range margin of sugar maple may well be maintained by a suite of interacting factors, such as temperature, interspecific competition, and herbivory. Sugar maple is preferentially favored over many boreal species by deer, and height growth is less responsive to warmer temperatures when browse pressure is high (Fisichelli et al. 2012), a dynamic that is further exacerbated by slower growth under cooler vs. warmer temperatures (Reich et al. 2015) and by slower growth relative to other boreal species (Fisichelli et al. 2015). Our study does not directly address sugar maple growth relative to that of competing species, and further research should examine whether climate-mediated growth responses shift the balance of competitive interactions at range margins.

Climate could also limit sugar maples' northern distribution through its effects on flower production or fertilization (Woodward 1990). Evidence of climate limitation for sugar maple at other life stages, however, is scant. Kellman (2004) measured lower germination of sugar maple seeds experimentally planted beyond range limits than for those within the range, but this was attributed to seed predation, and survival of germinants beyond the range exceeded within-range survival. At the furthest extent of the native distribution, there is no evidence of reproductive limitation in sugar maple; in these disjunct stands, recruitment is high and matches that within the range (Graignic et al. 2014, R. Putnam, personal observation).

Though sugar maple reproduction remains high at range margins, it is also possible that the northern margin reflects a climate threshold beyond which reproductive success declines sharply. High latitudes are characterized by growing seasons that are both cool and short; under such conditions, reproductive timing becomes critical. In a study of cocklebur, experimental transfers across a latitude gradient found that locally adapted populations at range margins reproduced earlier than populations elsewhere in the range (Griffith and Watson 2005), suggesting that reproductive timing is a key constraint at northern margins. Models incorporating phenology to predict survival and reproductive success in trees (see Chuine and Beaubien 2001) predict that sugar maple and many other species are limited in the north by lack of sufficient degree days for fruit maturation (Morin et al.2007). Experimental tests of these predictions for long-lived woody species are difficult, however; our study did not measure reproductive success of northern marginal populations.

\section{Range-limiting factors at the southern margin}

Range margins at low latitudes and altitudes, lacking cold temperatures as a limiting constraint, have been hypothesized to be limited instead by biotic interactions such as competition (MacArthur 1972, Kaufman 1995, Loehle 1998). Alternatively, it has been suggested that the lack of cold temperatures to meet chilling requirements might itself be limiting (Cannell and Smith 1986, Sykes et al. 1996, Guilbault et al. 2012); more frequent high heat and/or drought events might also be involved. In a recent comprehensive literature review on the rangelimiting dynamics at warm-edge margins (Cahill et al. 2014), no broadly shared constraint emerges: while there is evidence to support competition as the primary mechanism (e.g., Bullock et al. 2000, Cleavitt 2004, Dickinson et al. 2007), other studies support climate limitation through a variety of mechanisms (e.g., Macias et al. 2006 [aridity], Offord 2011 [frost damage, heat stress], Guilbault et al. 2012 [chilling requirements]). Few studies explicitly examine both biotic and abiotic limiting factors, but of those that do, there is some support for both having a range-limiting effect (e.g., Bruelheide 2003, Hara 2010).

Surprisingly, our data present no evidence to support limitation by either climate or competition at sugar maple's southern range edge: survival and growth of seedlings from all populations remained high beyond the southern range margin. It is worth noting that these beyond-range sites may have been even further outside of the species' climate envelope than would be suggested by the species' range map (Fig. 2) due to climate change over the past decades. Nevertheless, there was high seedling survival and growth at beyond-range southern sites even in the summer of 2011, the warmest summer at these sites in the past 40 years (Appendix S1: Fig. S1a). The experiment spanned years with above- and below-average temperature and precipitation, but annual analyses of seedling growth within sites and across years did not show a consistent growth response to increases in either temperature or precipitation, nor were variations in seedling survival across years linked to these weather patterns (results not shown).

Neither the clipping treatment of understory vegetation nor canopy gaps significantly enhanced survival or growth at southernmost sites, suggesting that the net aboveground impact of neighbors did not limit performance of sugar maple seedlings during the years of our experiment. In essence, the negative effects of competition may have been offset by positive effects of 
facilitation (Montgomery et al. 2010). High survival and growth of sugar maple beyond the southern range limit, however, does not exclude the possibility of competitive limitation: species with higher growth rates relative to sugar maple competing for canopy openings (see Yetter and Runkle 1986) could contribute to maintaining southern range margins. The effect of neighbors on target seedlings can also be positive at an early life stage but negative at another; for example, neighbors might facilitate seedling establishment but reduce either reproductive fitness of mature plants (Stanton-Geddes et al. 2012) or growth of seedlings over time (Wright et al. 2014).

While this study indicates two- to four-year-old sugar maple seedlings can survive and grow beyond the southern range limit, at least under the subset of climate conditions experienced during the three years of the experiment, the possibility of limitation in another life stage remains. Range limit models that incorporate both climate and phenology predict that sugar maple, along with other tree species, may be limited by lack of adequate chilling in the southern part of the range, causing them to be slow to break dormancy and late to flower, exposing immature fruits to frost damage in fall (Morin et al. 2007). We have no experimental data on flowering beyond the southern range margin, but in weekly phenology surveys in the spring of 2011, bud-break of seedlings was not delayed relative to other understory species, and the majority of seedlings in all populations had fully expanded leaves before the canopy closed (R. Putnam, personal observation).

Climatic constraints on germination could be another potential range-limiting mechanism for the species, as the seed requires one to three months of stratification under moist, near-freezing conditions for optimal germination (Godman et al. 1990). Germination of sugar maple seeds experimentally planted beyond the southern range limit in fall of 2010 was high, more than double the germination rate of those planted at sites within the range (R. Putnam, unpublished data), and it suggests that at least in some years, winters beyond the range limit are sufficiently cool to support germination of sugar maple seed. Rapid spring warming, however, can severely limit germination (Godman et al. 1990), and it is possible that the range is constrained by a combination of episodic germination success and dispersal limitation associated with a patchy distribution at the southern range edge.

\section{Biotic interactions}

Interactions between species can have strong effects on the local distribution of plants, thereby influencing species' distribution at a broader scale (Wisz et al. 2013). Interactions with a superior competitor, pathogen, or seed predator may restrict a species' range (e.g., Miller and Silander 1991, Matías and Jump 2012, Brown and Vellend 2014), while facilitative or mutualistic interactions with other species may expand a species' realized niche by mitigating stressful abiotic conditions (e.g., Choler et al. 2001, Afkhami et al. 2014); biotic interactions could also limit one range margin and extend the other (Cleavitt 2004). As climate changes, determining the extent of positive and negative biotic interactions at range margins is becoming increasingly important (Bruelheide 2003, HilleRisLambers et al. 2013). We expected interactions between seedlings and understory vegetation to shift across the range from competitive in the south to facilitative in the north. Instead, we found only modest (though significant) effects of competition across the range: driven primarily by the southern population, understory neighbors had a facilitative effect on seedlings in canopy gaps at and beyond the northern range margin and a competitive effect in both gaps and shade at southern sites.

Seedling growth was greater on average in clipped than in unclipped plots, and while the degree of understory neighbors' physiological effects on seedlings ("competitive intensity," sensu Welden and Slauson 1986) varied from site to site and among populations, the overall intensity of competition was relatively constant across the range for two of the three populations. At and beyond the southern range margin, where we hypothesized clipping would have an especially positive effect, we found no evidence to support competition as a range-limiting factor. While the lower neighbor densities achieved by clipping generally had a positive effect on seedlings, clipping had a negative effect on growth for the southern population at northern sites, which we attribute to abiotic stress. To fully assess the importance of competition at range margins, however, we would need site-specific quantitative measures of competition in the absence of abiotic stress; while a few studies have measured competition importance along gradients (Damgaard and Fayolle 2010, Kunstler et al. 2011), this approach has not been applied to range limits of woody species.

Canopy trees affect both light and belowground resource availability and abiotic stress, and differences between canopy gaps and the closed canopy were reflected in patterns of seedling survival and growth. We focus here primarily on the effects of canopy cover type, as previous research on sugar maple suggest that the effects on growth of canopy openness as it ranges from understory to gap equal or exceed those of soil moisture or nutrient availability (Walters and Reich 1997, 2000, Walters et al. 2014). A review of root competition in forests also found that for understory individuals, belowground competition with canopy trees is of secondary importance to light competition at all but the most xeric and nutrient poor sites (Coomes and Grubb 2000). We measured higher seedling survival and growth in gaps than in shade, but this effect was strongest at and beyond northern range margins. The relative decline in performance in southern gaps is suggestive of greater belowground resource competition and/or increasing stress; water loss, leaf temperatures, and photoinhibition all increase with higher light (Niinemets and Valladares 2004), and during 
the growing season these stressors are likely increasing along the temperature gradient.

Competitive success for a highly shade tolerant and slow-growing tree species such as sugar maple is not fully captured in measures of short-term survival and growth, as individuals must reach reproductive maturity and successfully outcompete other species to capture canopy openings. Growth of sugar maple seedlings in unclipped plots was fairly high beyond the northern range margin (for the northern population) and especially beyond the southern range margin (for all populations), but because the assemblage of potential competitors differs between within-range and beyond-range forest communities and the growth of competing species was not measured, we are unable to determine whether sugar maple would be able to successfully capture canopy gaps at these beyondrange sites.

It is possible that despite growth rates similar to or greater than those observed at within-range sites, sugar maple may be competitively excluded from the canopy beyond current range margins. Evidence in the literature suggests sugar maple growth rate relative to competitors is low even within the range. Sugar maple was one of the five most abundant canopy tree species in the understory at several sites in North Carolina, but its growth rate in canopy gaps was the second lowest of those species (Yetter and Runkle 1986). At the temperate-boreal forest ecotone at the northernmost extent of sugar maple's range in Minnesota, Fisichelli et al. (2015) recorded significantly lower height growth and leaf nitrogen content in sugar maple saplings compared to co-occurring balsam fir (A. alsamea), an abundant competitor typical of boreal forests; in contrast to balsam fir, sugar maple leaf nitrogen content was responsive to temperature and was higher at warmer sites (Fisichelli et al. 2015). Because photosynthetic rates of hardwood species such as sugar maple are more sensitive to foliar nitrogen concentrations than conifers (Reich et al. 1995), the species' contrasting responses to temperature could contribute to differences in growth and competitiveness between these two species at the temperate-boreal forest ecotone, especially as climate warms (Reich et al. 2015).

Though reducing understory vegetation density did not substantially enhance beyond-range seedling survival or growth, the effect of neighbors nonetheless changed with latitude. The stress gradient hypothesis predicts that facilitative interactions between species will outweigh competitive interactions under stressful conditions (Bertness and Callaway 1994, Choler et al. 2001, Callaway et al. 2002); in stressful abiotic environments, populations least adapted to those conditions may show the greatest facilitative benefit (Espeland and Rice 2007, Liancourt and Tielbörger 2011). Reciprocally transplanted seedlings in our experiment likely experienced varying levels of climate stress along the climate gradient, and populations might be expected to have greater stress at sites that differ climatically from their region of origin. Consistent with the stress gradient hypothesis and our expectation of highest climate stress in the population experiencing the greatest experimental climate transfer, seedlings from the southern provenance had higher final dry mass in unclipped plots at three of the four northernmost sites, suggesting this population experienced a net facilitative effect of neighbors at these sites. In contrast, northern and central population seedlings at these sites had higher final mass in clipped plots, suggesting net competitive interactions with neighbors predominated. Neighbors may moderate temperature and irradiance extremes (e.g., Castro et al. 2004) or ameliorate the seedling microclimate by reducing vapor pressure deficit (VPD; e.g., Muhamed et al. 2013), and where these stresses are limiting, such interactions could lead to a net positive effect on growth such as we observed.

We did not observe a corresponding facilitative effect of neighbors beyond the southern range margin, perhaps because the northern population did not experience as large a climate transfer in the first year. Mean summer temperatures in 2009 were cooler than average across the latitude gradient (Appendix S1: Fig. S1), so even at beyond-range southern sites, the northern population adjusted to transplanting under conditions typical of within-range sites, while at northern sites the abnormally cool summer further exacerbated the climate disconnect experienced by the southern population. Although some studies have suggested facilitation may play an important role at range limits in ameliorating marginal conditions (Germino et al. 2002, Castro et al. 2004), we did not find support for this, as the local (e.g., northern and southern) populations did not exhibit evidence of a net facilitative effect from neighbors when planted at northern and southern range boundaries.

\section{Population insights}

There is a long history of using reciprocal transplant experiments to understand differences in population response to the environment (e.g., Hall 1932, Hiesey 1940, Eriksson and Jonsson 1986, Hamann et al. 1998, Rehfeldt et al. 1999) and the implications of this variation in determining range limits (e.g., Levin and Clay 1984, Geber and Eckhart 2005). Across-range transfers highlight the degree to which populations are plastic in their response (Eckhart et al. 2004, Reich and Oleksyn 2008), though adaptation at range limits also occurs and may be rapid (Woodward 1990, Davis and Shaw 2001). Several authors recently have emphasized the need to study range-limiting effects of both biotic and abiotic factors at the population, rather than species, level, with a particular focus on range margins (Sexton et al. 2009, Hargreaves et al. 2014). In our study, the three populations differed in response to conditions across the range and at range margins in a manner suggestive of genetic variation among populations, and if these patterns are representative of intraspecific differentiation in sugar maple, it could have implications for both range-wide performance and dynamics at range boundaries. 
This study's inclusion of provenances from different parts of the range highlighted differences among the three provenances that underscore the importance of using more than one seed source to understand range constraints. Although overall sugar maple survival was positively correlated with temperature, which would seem to support climate limitation in the north, seedling sensitivity to temperature varied by population. Southern and central populations overwintered poorly at northern sites and experienced high seedling mortality, while the northern population had low mortality across the range. Even at a site more than $200 \mathrm{~km}$ north of the species' continuous distribution, $60 \%$ of seedlings from the northern provenance survived. While this study was not designed to elucidate differentiation among sugar maple populations, the northern population appeared to be more cold tolerant and could be differentiated from more southerly populations in any of a suite of traits associated with cold tolerance (Savage and Cavender-Bares 2013) that together have the potential to influence the current extent of the northern range margin.

Seedling performance varied along the latitude gradient in all three populations, but to differing degrees: both growth and survival of southern population seedlings were highly responsive to temperature growth and declined at northern sites, while northern populations had only slightly greater levels of growth and survival at southern than northern sites. At the five warmest sites, survival and growth of southern population seedlings exceeded that of central and northern-origin seedlings, but at cold northern sites northern population seedlings had highest survival and net growth. The central population was intermediate in its responsiveness to the summer temperature gradient: seedlings had higher mortality at northern sites, mirroring southern seedlings, but seedlings had similar net growth at northern and southern sites.

The patterns of intraspecific variation in net growth and survival that we observed between northern and southern populations are consistent with a cold hardiness and growth rate trade-off such as has been proposed as a range-limiting mechanism (MacArthur 1972, Woodward and Pigott 1975, Loehle 1998, Aitken and Hannerz 2001, Koehler et al. 2012). The southern, but not the northern, population had a steep decline in survival with increasing latitude driven by winter mortality. Summer mortality of southern seedlings was generally low across the range, but winter mortality was high in the northern half of the range and beyond range margins, and there, few southern seedlings survived beyond the first winter (Appendix S1: Fig. S5). First-year winter survival of northern population seedlings was two to four times higher than the southern population in the northern part of the range. At sites where its survival was high, however, the southern population consistently had higher net growth than the northern population, and though plants from both populations were larger at warmer sites, this was especially true of the southern population.
There could be alternative or complementary explanations for the observed differences in growth and survival patterns between northern and southern populations. It has recently been suggested that the apparent trade-off between cold hardiness and growth rate among willow species is driven by differing phenological cues for budburst, growth, and cold acclimation across the range that lead to differences in growth and survival (Savage and Cavender-Bares 2013). In botanic gardens, species from warmer climates were phenologically delayed in their response to environmental cues relative to species native to the climate, leading to predicted costs due to a shorter season for growth (Zohner and Renner 2014). Phenology constraints have been proposed as a range-limiting mechanism (Chuine 2010, Chapman et al. 2014), and there is some evidence for intraspecific variation as well in the timing of phenological processes such as leafing out and leaf abscission (Chuine et al. 2000, Morin et al. 2009, Vitasse et al. 2013).

High mortality among southern seedlings at northern sites could therefore potentially be explained not by lack of cold hardiness per se, but by a mismatch between environmental cues and phenology. Seedlings from the southern population leafed out slightly later in spring than northern seedlings and held their leaves longer in the fall (Fig. 11). A mismatch in phenology cues could cause a seedling to partially or fully miss the spring window before the canopy closes, which has been experimentally shown to have highly negative effects on growth and survival of sugar maple seedlings (Augspurger 2008). Later leaf senescence in the fall exposes leaves to freezing damage, and in willows is associated with higher loss of nitrogen due to poor nitrogen retranslocation (Weih 2009). Thus it is possible that seedlings from the southern population were losing the opportunity for carbon gain in the spring and experiencing added costs with holding leaves later in fall, a combined effect that may have reduced their growth and survival at northern sites.

Lower net growth of northern population seedlings relative to southern population seedlings at southern sites could be to some degree a consequence of a functionally shorter growing season rather than inherent lower potential maximum growth rate. Leaf abscission for seedlings from the northern population occurred much earlier in the fall than for the southern population (Fig. 11). Sugar maple is photosynthetically active in the fall prior to leaf senescence and accumulates carbon in root and stem tissue even after cessation of height growth (Horowitz et al. 2009), and the northern population's lower total growth at southern sites may thus be due in part to a lesser ability to capitalize on the long growing season.

While we are limited in the inference we can draw with only three populations, differences in net growth and survival among the populations suggest at least some degree of local adaptation. We did not measure reproductive fitness, but at both northern and southern range margins, the local population was taller and survived better than 
the other populations, which is consistent with previous genetic work on sugar maple (Kriebel and Gabriel 1969). Oney et al. (2013) proposed that intraspecific variation may buffer the effects of climate change at the species level by increasing the likelihood of differentiation in traits that could help the species persist, rather than migrate, with climate change. Southern range margins are generally considered especially vulnerable as the climate warms (Aitken et al. 2008), but the southern population had high survival and growth beyond current range margins, even during two warmer-than-average summers. Though the northern population had lower growth, its high survival under climate "warming" conditions simulated by across-range transplanting suggests that the northern population may also fare better than predicted with climate change.

\section{Other potential range-limiting factors}

The lack of strong evidence to support either climate or competition constraints on the range of sugar maple raises the possibility that either some other factor is responsible for limiting the range or that climate or competition are in fact constraining the range in some way that was not measured or characterized. We first address other possible factors that have been proposed as rangelimiting for this or other species, and then revisit competition and climate and discuss ways one or both might yet be limiting ranges.

While biotic stressors such as disease or insect herbivory are often considered of primarily local importance, the ability of exotic species in nonnative habitat to expand beyond their native niche, as suggested by the enemy release hypothesis (Keane and Crawley 2002), indicates that the range-limiting effects of pathogens, insects, and other herbivores may be underestimated (Mitchell and Power 2003, DeWalt et al. 2004, McCarthyNeumann and Ibáñez 2012, Gundale et al. 2013). A study on sugar maple's fungal seed pathogens, however, found similarly low levels of seed loss in forests dominated by conspecifics and heterospecifics (Kotanen 2007). While a variety of insects and leaf pathogens attack young sugar maple (Gardescu 2003), we did not find any consistent patterns in levels of foliar insect and disease damage across sites, and the effects were not correlated with seedling growth (data not shown).

Deer herbivory has been suggested as one potential factor contributing to regeneration failure of sugar maple at a site in the southern part of the range (Belden and Pallardy 2009) and high browse pressure from deer at the boreal forest ecotone is especially limiting for temperate species (Fisichelli et al. 2012). In extreme cold climates where growth rates are temperature limited, ungulate herbivory can restrict trees from areas where they would otherwise be able to grow (Speed et al. 2010). At the landscape scale in more moderate climates, however, deer density does not appear to be correlated with reproductive success of sugar maple (Didier and Porter 2003).
At range margins where the favorability of a habitat may be determined by microclimates, species may experience a functionally fragmented landscape and have a lower likelihood of encountering small pockets of habitat where the environment is suitable (Bahn et al. 2006, Löhmus et al. 2014). Even in the absence of an environmental gradient, stable range limits can emerge if the distribution of suitable habitat on the landscape becomes so patchy that dispersal can't overcome the distance (Keitt et al. 2001). We intentionally selected beyond-range sites that were as similar to within-range sites as possible, and thus our results do not necessarily reflect the general suitability of beyond-range forests for sugar maple.

Despite our efforts to choose sites that were similar, the planted sugar maple seedlings survived and grew on soils that varied in acidity (Table 1) and fertility. Only soil pH was measured in this study, but the reduction in bioavailability of soil nutrients and increase in uptake of toxic metals on acidic soils is well understood (St. Clair and Lynch 2005). Though sugar maple is sensitive to acidic soils and observed declines in sugar maple health in the northeastern United States have been linked to calcium and magnesium deficiencies (St. Clair et al. 2008), evidence from this study shows that soils are not directly limiting the western portion of sugar maple's range either through poor survival or attenuated growth. Drought, freeze/thaw cycles, and defoliation by insects or deer can all compound nutrient stress (St. Clair et al. 2008), however, and nutrient stress is one of many factors that could combine to limit sugar maple under otherwise marginal conditions.

The latitude transect selected for this study captured a strong temperature gradient, but the moisture gradient is less clearly associated with latitude. The experiment did, however, span both wetter-than-average and drierthan-average years (Appendix S1: Fig. S1b), and coupled with similar variation in temperature across years (Appendix S1: Fig. S1a), it is likely that seedlings experienced soil water stress in at least some years of the experiment. Sugar maple seedling growth has been shown to be higher at moist, rich sites (Walters and Reich 1997), and drought has been associated with sugar maple dieback and decline (Kolb and McCormick 1993). Soil moisture data were not collected in this experiment, but in models, sugar maple's western range boundary is driven by soil water stress (Walker et al. 2002), and though the species' overall distribution is only very weakly influenced by soil moisture (Chuine and Beaubien 2001), populations might have had contrasting survival and growth responses to water limitation.

Belowground competition for soil water and nutrients between planted sugar maple seedlings and understory neighbors, though not controlled for in this experiment, might have been important, and experimental pairings of root competition "contests" suggests that the outcome of competition for nutrients or water may very much depend on the identity of the competitor (Armas and Pugnaire 2011). Other belowground interactions could also affect plant growth: in one study, removing local soil biota 
through soil sterilization shifted the balance of competitive interactions between two woody species (Chen et al. 2012), while in another, communities of soil microorganisms adapted to local soil moisture conditions ameliorated the effects of drought on plant fitness (Lau and Lennon 2012). Above- and belowground resource gradients may interact to affect seedling performance, and the effect depends on the species (Coomes and Grubb 2000, Ibáñez and McCarthy-Neumann 2014). While there is evidence from a range of studies that sugar maple performance in the understory is primarily influenced by light availability (e.g., Walters and Reich 1997, Ricard et al. 2003, Ibáñez and McCarthy-Neumann 2014, Walters et al. 2014), belowground resources have been shown to matter in some cases (Walters and Reich 1997, 2000, Walters et al. 2014), and we do not know the extent and direction of belowground effects on sugar maple survival or growth at our experimental sites.

This experiment manipulated neighboring plants and reduced aboveground competition through aboveground biomass removal; the degree to which this treatment affected belowground interactions remains unknown, though the observed reductions in aboveground regrowth following successive clipping treatments could be suggestive of a reduction in belowground biomass of targeted plants. However, vegetation removal enables only the net effect of neighbors to be determined and does not allow above- and belowground processes to be distinguished (Montgomery et al. 2010), and the full extent of biotic interactions occurring at sites across the range may therefore have been masked by concurrent above- and belowground interactions in opposing directions. When above- and belowground competition were examined separately for red maple (Acer rubrum) and five other woody species in forest understory and gaps, however, belowground neighbor interactions consistently had either a negative or neutral effect on seedlings (Montgomery et al. 2010). The competitive effect we observed is therefore likely conservative and may well underestimate the magnitude of neighbor interactions.

Plots were not root trenched, a manipulation that would have reduced belowground interactions with canopy trees. A root trenching experiment of sugar maple and other species in Quebec found no effect on sapling height or diameter growth, which was attributed to the overriding importance of light competition (Ricard et al. 2003). Another experiment found root trenching had a positive effect on seedling height and mass at low light but did not affect survival or biomass distribution between shoots and roots (Machado et al. 2003), while a review of root trenching experiments concluded that light limits seedling growth at sites with rich moist soils and root trenching has a positive effect on growth primarily on drier, nutrient-poor soils (Coomes and Grubb 2000). These studies suggest that while belowground competition with overstory individuals can affect seedling growth, light competition is of primary importance in the forest understory.
Unlike range limit studies of herbaceous plants, the timespan from germination to reproductive maturity for woody plants is not conducive to ecological experiments. An important caveat to this study is the possibility that the factors limiting sugar maple's distribution, whether climate, competition, or some combination of factors, constrain a life stage other than the seedling. Perhaps most importantly, this study could not address flowering or the production of fertile seed, processes that could be limiting the distribution either through direct climate limitation or through phenology (Morin et al. 2007). If fecundity was low or sporadic at range margins, sugar maple might be unable to maintain a population beyond current range margins.

In this study, we have been focused on spatial variation of deterministic factors and their effects on a subset of demographic parameters, but environmental or demographic stochasticity could also limit distributions, particularly if population size or growth rate at range limits was low or the availability of suitable habitat was limited (Holt et al. 2005). Marginal populations might have more variable rates of survival (Angert 2009), recruitment (Lesica 2014), or population growth rate (Eckhart et al. 2011), potentially affecting the extent of the species' realized niche. This study was not designed to quantify any of these sources of variability, but these factors may play a role in constraining the distribution of some species, especially in the context of changing climate (Nabel et al. 2013).

\section{Conclusions}

Climate change presents a variety of potential challenges for plants; changing patterns of temperature, precipitation, and their attendant effects on growth, survival, and phenology may affect patterns of distribution and lead to novel assemblages of competitors. Examining plant survival and growth responses to climate in the context of biotic interactions such as competition and facilitation, as well as other biotic interactions such as pathogens that were not addressed in this study, is therefore critical.

We found survival and growth of sugar maple seedlings varied across the range and beyond range margins, with the nature and strength of effects influenced by the latitude of population origin. Contrary to our expectations, however, we did not find evidence that climate or competition limited survival or growth of northern or southern populations when experimentally transplanted beyond their respective range margins, which raises the possibility that neither is as strong or immediate a rangelimiting constraint as is generally assumed. Alternatively, it is plausible that climate and/or biotic factors may impose constraints that are beyond the scope of our study to detect. Over the long term, climate-mediated effects on phenology and growth may shift the competitive balance between species (Savage and Cavender-Bares 2013, Rawal et al. 2014), which in turn has the potential to 
influence species' distributions (Chuine and Beaubien 2001). Future studies of tree species' range limits should compare the phenology and reproductive success of mature stands within the range and near range margins and examine the focal species' phenology and reproductive success relative to that of other competing species in the forest community.

The natural forest environment of this experiment sets this study apart from many range-limit studies (reviewed by Hargreaves et al. 2014) and enabled a nuanced examination of biotic interactions with canopy and understory plants along a climate gradient. Seedling performance in this ecologically realistic context not only gives important insight into regeneration dynamics under a range of abiotic conditions but also potential responses to changing climate. While temperatures at warmer, beyond-range southern sites did not limit survival and net growth in the three years of this experiment, future climate shifts - which are unknown and potentially more extreme in magnitude and/or variability - could lead to changes in phenology, reproductive success, and competitive dynamics that would have implications for the extent and location of range boundaries.

\section{ACKNOWLEDGMENTS}

This research has been supported by funding from the Wilderness Research Foundation, and by fellowships from the Environmental Protection Agency, the Alexander \& Lydia Anderson Fellowship Fund, the James W. Wilkie Fund for Natural History, the Carolyn M. Crosby Fellowship Fund, the Rothman Fellowship Fund of the Department of Ecology, Evolution, and Behavior, and a Thesis Research Grant from the University of Minnesota. The authors wish to thank two anonymous reviewers for their helpful suggestions that improved the manuscript. Earlier stages of this project benefitted from feedback and ideas from N. Fisichelli, S. Lodge, J. Stanton-Geddes, J. Savage, and P. Wragg. Thanks to all who helped with field work, especially A. Holzer, V. McDaniels, R. and P. Mayer, R. Stich, N. Brennan, S. Lodge, T. Serres, S. Wang, S. Bartels, C. Zhao, and J. Lewis. We thank the following people for assisting in securing access to research sites: E. Iskra, D. Brunner, R. Horn, J. Lewis, B. Palik, D. Engstrom, J. Pearson, S. Pallardy, K. Hosman, M. Spetich, R. Chaney, and J. Guldin.

\section{Literature Cited}

Afkhami, M. E., P. J. McIntyre, and S. Y. Strauss. 2014. Mutualist-mediated effects of species' range limits across large geographic scales. Ecology Letters 17:1265-1273.

Aitken, S. N., and M. Hannerz. 2001. Genecology and gene resource management strategies for conifer cold hardiness. Pages 23-53 in F. J. Bigras and S. J. Columbo, editors. Conifer cold hardiness. Kluwer Academic Publishers, Dordrecht, The Netherlands.

Aitken, S. N., S. Yeaman, J. A. Holliday, T. Wang, and S. Curtis-McLane. 2008. Adaptation, migration, or extirpation: climate change outcomes for tree populations. Evolutionary Applications 1:95-111.

Angert, A. L. 2009. The niche, limits to species' distributions, and spatiotemporal variation in demography across the elevation ranges of two monkeyflowers. Proceedings of the National Academy of Sciences USA 106:19693-19698.
Araújo, M. B., and M. Luoto. 2007. The importance of biotic interactions for modeling species distributions under climate change. Global Ecology and Biogeography 16:743-753.

Armas, C., and F. I. Pugnaire. 2011. Plant neighbor identity matters to belowground interactions under controlled conditions. PLoS ONE 6:e27791.

Asselin, H., S. Payette, M.-J. Fortin, and S. Vallée. 2003. The northern limit of Pinus banksiana Lamb. in Canada: explaining the difference between the eastern and western distributions. Journal of Biogeography 30:1709-1718.

Augspurger, C. K. 2008. Early spring leaf out enhances growth and survival of saplings in a temperate deciduous forest. Oecologia 156:281-286.

Augspurger, C. K. 2009. Spring 2007 warmth and frost: phenology, damage and refoliation in a temperate deciduous forest. Functional Ecology 23:1031-1039.

Bahn, V., R. J. O'Connor, and W. B. Krohn. 2006. Effect of dispersal at range edges on the structure of species ranges. Oikos 115:89-96.

Barras, N., and M. Kellman. 1998. The supply of regeneration micro-sites and segregations of tree species in a hardwood/ boreal forest transition zone. Journal of Biogeography 25: 871-881.

Beaudet, M., and C. Messier. 1998. Growth and morphological responses of yellow birch, sugar maple, and beech seedlings growing under a natural light gradient. Canadian Journal of Forest Research 28:1007-1015.

Belden, A. C., and S. G. Pallardy. 2009. Successional trends and apparent Acer saccharum regeneration failure in an oakhickory forest in central Missouri, USA. Plant Ecology 204: 305-322.

Berkowitz, A. R., C. D. Canham, and V. R. Kelly. 1995. Competition vs. facilitation of tree seedling growth and survival in early successional communities. Ecology 76 : 1156-1168.

Bertness, M. D., and R. Callaway. 1994. Positive interactions in communities. Trends in Ecology and Evolution 9: 191-193.

Boisvert-Marsh, L., C. Périé, and S. de Blois. 2014. Shifting with climate? Evidence for recent changes in tree species distribution at high latitudes. Ecosphere 5:art83.

Brooker, R. W., et al. 2008. Facilitation in plant communities: the past, the present, and the future. Journal of Ecology 96:18-34.

Brown, C. D., and M. Vellend. 2014. Non-climatic constraints on upper elevational plant range expansion under climate change. Proceedings of the Royal Society B 281:20141779.

Bruelheide, H. 2003. Translocation of a montane meadow to simulate the potential impact of climate change. Applied Vegetation Science 6:23-34.

Bruno, J. F., J. J. Stachowicz, and M. D. Bertness. 2003. Inclusion of facilitation into ecological theory. Trends in Ecology and Evolution 18:119-125.

Bulgarella, M., S. A. Trewick, N. A. Minards, M. J. Jacobson, and M. Morgan-Richards. 2014. Shifting ranges of two tree weta species (Hemideina spp.): competitive exclusion and changing climate. Journal of Biogeography 41:524-535.

Bullock, J. M., R. J. Edwards, P. D. Carey, and R. J. Rose. 2000. Geographical separation of two Ulex species at three spatial scales: Does competition limit species' ranges? Ecography 23:257-271.

Cahill, A. E., M. E. Aiello-Lammens, M. C. Fisher-Reid, X. Hua, C. J. Karanewsky, H. Y. Ryu, G. C. Sbeglia, F. Spagnolo, J. B. Waldron, and J. J. Wiens. 2014. Causes of warm-edge range limits: systematic review, proximate factors and implications for climate change. Journal of Biogeography 41:429-442. 
Callaway, R. M., and L. R. Walker. 1997. Competition and facilitation: a synthetic approach to interactions in plant communities. Ecology 78:1958-1965.

Callaway, R. M., et al. 2002. Positive interactions among alpine plants increase with stress. Nature 417:844-848.

Canham, C. D., A. R. Berkowitz, V. R. Kelly, G. M. Lovett, S. V. Ollinger, and J. Schnurr. 1996. Biomass allocation and multiple resource limitation in tree seedlings. Canadian Journal of Forest Research 26:1521-1530.

Cannell, M. G. R., and R. I. Smith. 1986. Climatic warming, spring budburst and frost damage on trees. Journal of Applied Ecology 23:177-191.

Caplat, P., M. Anand, and C. Bauch. 2008. Interactions between climate change, competition, dispersal, and disturbances in a tree migration model. Theoretical Ecology 1:209-220.

Case, T. J., and M. L. Taper. 2000. Interspecific competition, environmental gradients, gene flow, and the coevolution of species' borders. American Naturalist 155:583-605.

Castro, J., R. Zamora, J. A. Hódar, and J. M. Gómez. 2004. Seedling establishment of a boreal tree species (Pinus sylvestris) at its southernmost distribution limit: consequences of being in a marginal Mediterranean habitat. Journal of Ecology 92:266-277.

Chapman, D. S., T. Haynes, S. Beal, F. Essl, and J. M. Bullock. 2014. Phenology predicts the native and invasive range limits of common ragweed. Global Change Biology 20:192-202.

Chen, H., R. Q. Wang, X. L. Ge, J. Zhang, N. Du, W. Wang, and J. Liu. 2012. Competition and soil fungi affect the physiological and growth traits of an alien and a native tree species. Photosynthetica 50:77-85.

Choler, P., R. Michalet, and R. M. Callaway. 2001. Facilitation and competition on gradients in alpine plant communities. Ecology 82:3295-3308.

Chuine, I. 2010. Why does phenology drive species distribution? Philosophical Transactions of the Royal Society B 365: 3149-3160.

Chuine, I., and E. G. Beaubien. 2001. Phenology is a major determinant of tree species range. Ecology Letters 4:500-510.

Chuine, I., J. Belmonte, and A. Mignot. 2000. A modeling analysis of the genetic variation of phenology between tree populations. Journal of Ecology 88:561-570.

Cleavitt, N. 2004. Comparative ecology of a lowland and a subalpine species of Mnium in the northern Rocky Mountains. Plant Ecology 174:205-216.

Cole, W. G., and C. G. Lorimer. 2005. Probabilities of smallgap capture by sugar maple saplings based on height and crown growth data from felled trees. Canadian Journal of Forest Research 35:643-655.

Coomes, D. A., and P. J. Grubb. 2000. Impacts of root competition in forests and woodlands: a theoretical framework and review of experiments. Ecological Monographs 70:171-207.

Cunningham, H. R., L. J. Rissler, and J. J. Apodaca. 2009. Competition at the range boundary in the slimy salamander: using reciprocal transplants for studies on the role of biotic interactions in spatial distributions. Journal of Animal Ecology 78:52-62.

Damgaard, C., and A. Fayolle. 2010. Measuring the importance of competition: a new formulation of the problem. Journal of Ecology 98:1-6.

Darwin, C. 1859 . On the origin of species by means of natural selection or the preservation of favored races in the struggle for life. John Murray, London, UK.

Davis, M. B., and R. G. Shaw. 2001. Range shifts and adaptive responses to Quaternary climate change. Science 292: 673-679.

De Kort, H., K. Vandepitte, H. H. Bruun, D. Closset-Kopp, O. Honnay, and J. Mergeay. 2014. Landscape genomics and a common garden trial reveal adaptive differentiation to temperature across Europe in the tree species Alnus glutinosa. Molecular Ecology 23:4709-4721.

DeWalt, S. J., J. S. Denslow, and K. Ickes. 2004. Natural-enemy release facilitates habitat expansion of the invasive tropical shrub Clidemia hirta. Ecology 85:471-483.

Dickie, I. A., S. A. Schnitzer, P. B. Reich, and S. E. Hobbie. 2005. Spatially disjunct effects of co-occurring competition and facilitation. Ecology Letters 8:1191-1200.

Dickinson, K. J. M., D. Kelly, A. F. Mark, G. Wells, and R. Clayton. 2007. What limits a rare alpine plant species? Comparative demography of three endemic species of Myosotis (Boraginaceae). Austral Ecology 32:155-168.

Didier, K. A., and W. F. Porter. 2003. Relating spatial patterns of sugar maple reproductive success and relative deer density in northern New York State. Forest Ecology and Management 181:253-266

Doak, D. F., and W. F. Morris. 2010. Demographic compensation and tipping points in climate-induced range shifts. Nature 467:959-962.

Dobzhansky, T. 1950. Evolution in the tropics. American Scientist 38:209-221.

Dudley, S. A., and J. Schmitt. 1995. Genetic differentiation in morphological responses to simulated foliage shade between populations of Impatiens capensis from open and woodland sites. Functional Ecology 9:655-666.

Eckhart, V. M., M. A. Geber, and C. M. McGuire. 2004. Experimental studies of adaptation in Clarkia xantiana. I. Sources of trait variation across a subspecies border. Evolution 58:59-70.

Eckhart, V. M., M. A. Geber, W. F. Morris, E. S. Fabio, P. Tiffin, and D. A. Moeller. 2011. The geography of demography: long-term demographic studies and species distribution models reveal a species border limited by adaptation. American Naturalist 178:S26-S43.

Engler, R., C. F. Randin, P. Vittoz, T. Czáka, M. Beniston, N. E. Zimmermann, and A. Guisan. 2009. Predicting future distributions of mountain plants under climate change: Does dispersal capacity matter? Ecography 32:34 45 .

Eriksson, G., and A. Jonsson. 1986. A review of the genetics of Betula. Scandinavian Journal of Forest Research 1:421-434.

Espeland, E., and K. Rice. 2007. Facilitation across stress gradients: the importance of local adaptation. Ecology 88: 2404-2409.

Fisichelli, N., L. E. Frelich, and P. B. Reich. 2012. Sapling growth responses to warmer temperatures 'cooled' by browse pressure. Global Change Biology 18:3455-3463.

Fisichelli, N., A. Stefanski, L. Frelich, and P. Reich. 2015. Temperature and leaf nitrogen affect performance of plant species at range overlap. Ecosphere 6:art186.

Gardescu, S. 2003. Herbivory, disease, and mortality of sugar maple seedlings. Northeastern Naturalist 10:253-268.

Gaston, K. J. 2009. Geographic range limits: achieving synthesis. Proceedings of the Royal Society B 276:1395-1406.

Geber, M. A., and V. M. Eckhart. 2005. Experimental studies of adaptation in Clarkia xantiana. II. Fitness variation across a subspecies border. Evolution 59:521-531.

Germino, M. J., W. K. Smith, and A. C. Resor. 2002. Conifer seedling distribution and survival in an alpine-treeline ecotone. Plant Ecology 162:157-168.

Giesecke, T., P. A. Miller, M. T. Sykes, A. E. K. Ojala, H. Seppä, and R. H. W. Bradshaw. 2010. The effect of past changes in inter-annual temperature variability on tree distribution limits. Journal of Biogeography 37:1394-1405.

Godman, R. M., H. W. Yawney, and C. H. Tubbs. 1990. Acer saccharum Marsh. Sugar maple. Pages 78-91 in R. Burns and B. Honkala, editors. Silvics of North America. Volume 2. 
Hardwoods. U.S. Department of Agriculture, Forest Service, Washington, D.C., USA.

Gómez-Aparicio, L., R. Zamora, J. Castro, and J. A. Hódar. 2008. Facilitation of tree saplings by nurse plants: microhabitat amelioration or protection against herbivores? Journal of Vegetation Science 19:161-172.

Grace, J. 1987. Climatic tolerance and the distribution of plants. New Phytologist 106:113-130.

Graignic, N., F. Tremblay, and Y. Bergeron. 2014. Geographical variation in reproductive capacity of sugar maple (Acer saccharum Marshall) northern peripheral populations. Journal of Biogeography 41:145-157.

Griffith, T. M., and M. A. Watson. 2005. Stress avoidance in a common annual: reproductive timing is important for local adaptation and geographic distribution. Journal of Evolutionary Biology 18:1601-1612.

Gross, S. J., and T. D. Price. 2000. Determinants of the northern and southern range limits of a warbler. Journal of Biogeography 27:869-878.

Guilbault, K. R., C. S. Brown, J. M. Friedman, and P. B. Shafroth. 2012. The influence of chilling requirement on the southern distribution limit of exotic Russian olive (Elaeagnus angustifolia) in western North America. Biological Invasions 14:1711-1724.

Gundale, M. J., P. Kardol, M.-C. Nilsson, U. Nilsson, R. W. Lucas, and D. A. Wardle. 2013. Interactions with soil biota shift from negative to positive when a tree species is moved outside its native range. New Phytologist 202:415-421.

Gunter, L. E., G. A. Tuskan, C. A. Gunderson, and R. J. Norby. 2000. Genetic variation and spatial structure in sugar maple (Acer saccharum Marsh.) and implications for predicted global-scale environmental change. Global Change Biology 6:335-344.

Hall, H. M. 1932. Heredity and environment — as illustrated by transplant studies. Scientific Monthly 35:289-302.

Hamann, A., Y. A. El-Kassaby, M. P. Koshy, and G. Namkoong. 1998. Multivariate analysis of allozymic and quantitative trait variation in Alnus rubra: geographic patterns and evolutionary implications. Canadian Journal of Forest Research 28:1557-1565.

Hamrick, J. L. 2004. Response of forest trees to global environmental changes. Forest Ecology and Management 197: 323-335.

Hara, M. 2010. Climatic and historical factors controlling horizontal and vertical distribution patterns of two sympatric beech species, Fagus crenata Blume and Fagus japonica Maxim., in eastern Japan. Flora 205:161-170.

Hargreaves, A. L., K. E. Samis, and C. G. Eckert. 2014. Are species' range limits simply niche limits writ large? A review of transplant experiments beyond the range. American Naturalist 183:157-173.

Hett, J. M., and O. L. Loucks. 1971. Sugar maple (Acer saccharum Marsh.) seedling mortality. Journal of Ecology 59: 507-520.

Hiesey, W. M. 1940. Environmental influence and transplant experiments. Botanical Review 6:181-203.

HilleRisLambers, J., M. A. Harsch, A. K. Ettinger, K. R. Ford, and E. J. Theobald. 2013. How will biotic interactions influence climate change-induced range shifts? Annals of the New York Academy of Sciences 1297:112-125.

Holt, R. D. 2003. On the evolutionary ecology of species' ranges. Evolutionary Ecology Research 5:159-178.

Holt, R. D., T. H. Keitt, M. A. Lewis, B. A. Maurer, and M. L. Taper. 2005. Theoretical models of species' borders: single species approaches. Oikos 108:18-27.

Horowitz, M. E., T. J. Fahey, J. B. Yavitt, T. R. Feldpausch, and R. E. Sherman. 2009. Patterns of late-season photosynthate movement in sugar maple saplings. Canadian Journal of Forest Research 39:2294-2298.

Hutchinson, G. E. 1957. Concluding remarks. Cold Spring Harbor Symposia on Quantitative Biology 22:415-427.

Ibáñez, I., and S. McCarthy-Neumann. 2014. Integrated assessment of the direct and indirect effects of resource gradients on tree species recruitment. Ecology 95:364-375.

Inouye, D. W. 2000. The ecological and evolutionary significance of frost in the context of climate change. Ecology Letters 3:457-463.

Iverson, L. R., M. W. Schwartz, and A. M. Prasad. 2004. How fast and far might tree species migrate in the eastern United Sates due to climate change? Global Ecology and Biogeography 13:209-219.

Jump, A. S., and J. Peñuelas. 2005. Running to stand still: adaptation and the response of plants to rapid climate change. Ecology Letters 8:1010-1020.

Kaufman, D. M. 1995. Diversity of New World mammals: universality of the latitudinal gradients of species and bauplans. Journal of Mammalogy 76:322-334.

Keane, R. M., and M. J. Crawley. 2002. Exotic plant invasions and the enemy release hypothesis. Trends in Ecology and Evolution 17:164-170.

Keitt, T. H., M. A. Lewis, and R. D. Holt. 2001. Allee effects, invasion pinning, and species' borders. American Naturalist 157:203-216.

Kellman, M. 2004. Sugar maple (Acer saccharum Marsh.) establishment in boreal forest: results of a transplantation experiment. Journal of Biogeography 31:1515-1522.

Kirkpatrick, M., and N. H. Barton. 1997. Evolution of a species' range. American Naturalist 150:1-23.

Klimeš, L., and J. Doležal. 2010. An experimental assessment of the upper elevational limit of flowering plants in the western Himalayas. Ecography 33:590-596.

Koehler, K., A. Center, and J. Cavender-Bares. 2012. Evidence for a freezing tolerance-growth rate trade-off in the live oaks (Quercus series Virentes) across the tropical-temperate divide. New Phytologist 193:730-744.

Kolb, T. E., and L. H. McCormick. 1993. Etiology of sugar maple decline in four Pennsylvania stands. Canadian Journal of Forest Research 23:2395-2402.

Kollas, C., C. Körner, and C. F. Randin. 2014. Spring frost and growing season length co-control the cold range limits of broad-leaved trees. Journal of Biogeography 41:773-783.

Kotanen, P. M. 2007. Effects of fungal seed pathogens under conspecific and heterospecific trees in a temperate forest. Canadian Journal of Botany 85:918-925.

Kreyling, J., S. Schmid, and G. Aas. 2015. Cold tolerance of tree species is related to the climate of their native ranges. Journal of Biogeography 42:156-166.

Kreyling, J., et al. 2014. Local adaptations to frost in marginal and central populations of the dominant forest tree Fagus sylvatica L. as affected by temperature and extreme drought in common garden experiments. Ecology and Evolution 4:594-605.

Kriebel, H. B., and W. J. Gabriel. 1969. Genetics of sugar maple. Forest Service Research Paper WO-7. U.S. Department of Agriculture, Washington, D.C., USA.

Kullman, L. 2002. Rapid recent range-margin rise of tree and shrub species in the Swedish Scandes. Journal of Ecology 90:68-77.

Kunstler, G., C. H. Albert, B. Courbaud, S. Lavergne, W. Thuiller, G. Vieilledent, N. E. Zimmermann, and D. A. Coomes. 2011. Effects of competition on tree radial-growth vary in importance but not in intensity along climatic gradients. Journal of Ecology 99:300-312.

Lane, C. J., D. D. Reed, G. D. Mroz, and H. O. Liechty. 1993. Width of sugar maple (Acer saccharum) tree rings as affected 
by climate. Canadian Journal of Forest Research 23: $2370-2375$.

Lau, J. A., and J. T. Lennon. 2012. Rapid responses of soil microorganisms improve plant fitness in novel environments. Proceedings of the National Academy of Sciences USA 109:14058-14062.

Lesica, P. 2014. Low recruitment not mortality limits growth of peripheral populations of Silene spaldingii. Botany-Botanique 92:340-347.

Levin, D. A., and K. Clay. 1984. Dynamics of synthetic Phlox drummondii populations at the species margin. American Journal of Botany 71:1040-1050.

Liancourt, P., and K. Tielbörger. 2011. Ecotypic differentiation determines the outcome of positive interactions in a dryland annual plant species. Perspectives in Plant Ecology, Evolution and Systematics 13:259-264.

Little, E. L. Jr. 1971. Atlas of United States trees. Volume 2. Conifers and important hardwoods. Miscellaneous Publication 1146. U.S. Department of Agriculture, Washington, D.C.

Loehle, C. 1998. Height growth rate tradeoffs determine northern and southern range limits for trees. Journal of Biogeography 25:735-742.

Löhmus, K., T. Paal, and J. Liira. 2014. Long-term colonization ecology of forest-dwelling species in a fragmented rural landscape - dispersal versus establishment. Ecology and Evolution 4:3113-3126.

Lu, P. W. H., M. Parker, S. Cherry, W. C. Colombo, R. Man Parker, and N. Roubal. 2014. Survival and growth patterns of white spruce (Picea glauca [Moench] Voss) rangewide provenances and their implications for climate change adaptation. Ecology and Evolution 4:2360-2374.

MacArthur, R. H. 1972. Geographical ecology: patterns in the distribution of species. Harper \& Row Publishers, New York, New York, USA.

Machado, J.-L., M. B. Walters, and P. B. Reich. 2003. Belowground resources limit seedling growth in forest understories but do not alter biomass distribution. Annals of Forest Science 60:319-330.

Macias, M., L. Andreu, O. Bosch, J. J. Camarero, and E. Gutiérrez. 2006. Increasing aridity is enhancing silver fir (Abies alba Mill.) water stress in its south-western distribution limit. Climatic Change 79:289-313.

Maher, E. L., M. J. Germino, and N. J. Hasselquist. 2005. Interactive effects of tree and herb cover on survivorship, physiology, and microclimate of conifer seedlings at the alpine tree-line ecotone. Canadian Journal of Forest Research 35:567-574.

Marsico, T. D., and J. J. Hellman. 2009. Dispersal limitation inferred from an experimental translocation of Lomatium (Apiaceae) species outside their geographic ranges. Oikos 118:1783-1792.

Matías, L., and A. S. Jump. 2012. Interactions between growth, demography, and biotic interactions in determining species range limits in a warming world: the case of Pinus sylvestris. Forest Ecology and Management 282:10-22.

McCarragher, S. R., D. Goldblum, and L. S. Rigg. 2011. Geographic variation of germination, growth, and mortality in sugar maple (Acer saccharum): common garden and reciprocal dispersal experiments. Physical Geography 32: $1-21$.

McCarthy-Neumann, S., and I. Ibáñez. 2012. Tree range expansion may be enhanced by escape from negative plant-soil feedbacks. Ecology 93:2637-2649.

McKenney, D. W., J. H. Pedlar, R. B. Rood, and D. Price. 2011. Revisiting projected shifts in the climate envelopes of North American trees using updated general circulation models. Global Change Biology 17:2720-2730.
Meier, E. S., F. Kienast, P. B. Pearman, J.-C. Svenning, W. Thuiller, M. B. Araújo, A. Guisan, and N. E. Zimmermann. 2010. Biotic and abiotic variables show little redundancy in explaining tree species distributions. Ecography 33:1038-1048.

Michalet, R., C. Schöb, C. J. Lortie, R. W. Brooker, and R. M. Callaway. 2014. Partitioning net interactions among plants along altitudinal gradients to study community responses to climate change. Functional Ecology 28:75-86.

Miller, G. A., and J. A. Silander Jr. 1991. Control of the distribution of giant rosette species of Puya (Bromeliaceae) in the Ecuadorian Páramos. Biotropica 23:124-133.

Miller, M. D., and K. C. Parker. 2009. The impacts of the Appalachian mountains on the post-glacial migration pathways and gene flow of sugar maple (Acer saccharum). Physical Geography 30:89-104.

Mitchell, C. E., and A. G. Power. 2003. Release of invasive plants from fungal and viral pathogens. Nature 421: 625-627.

Moeller, D. A., M. A. Geber, V. M. Eckhart, and P. Tiffin. 2012. Reduced pollinator service and elevated pollen limitation at the geographic range limit of an annual plant. Ecology 93:1036-1048

Molina-Montenegro, M. A., J. Gallardo-Cerda, T. S. M. Flores, and C. Atala. 2012. The trade-off between cold resistance and growth determines the Nothofagus pumilio treeline. Plant Ecology 213:133-142.

Montgomery, R. A., P. B. Reich, and B. J. Palik. 2010. Untangling positive and negative biotic interactions: views from above and below ground in a forest ecosystem. Ecology 91:3641-3655.

Morin, X., C. Augspurger, and I. Chuine. 2007. Process-based modeling of species' distributions: What limits temperate tree species' range boundaries? Ecology 88:2280-2291.

Morin, X., M. J. Lechowicz, C. Augspurger, J. O'Keefe, D. Viner, and I. Chuine. 2009. Leaf phenology in 22 North American tree species during the 21 st century. Global Change Biology 15:961-975.

Muhamed, H., B. Touzard, Y. Le Bagousse-Pinguet, and R. Michalet. 2013. The role of biotic interactions for the early establishment of oak seedlings in coastal dune forest communities. Forest Ecology and Management 297:67-74.

Munson, S. M. 2013. Plant responses, climate pivot points, and trade-offs in water-limited ecosystems. Ecosphere 4:1-13.

Nabel, J. E. M. S., N. Zurbriggen, and H. Lischke. 2013. Interannual climate variability and population density thresholds can have a substantial impact on simulated tree species' migration. Ecological Modelling 257:88-100.

Niinemets, Ü., and F. Valladares. 2004. Photosynthetic acclimation to simultaneous and interacting environmental stresses along natural light gradients: optimality and constraints. Plant Biology 6:254-268.

Offord, C. A. 2011. Pushed to the limit: consequences of climate change for the Araucariaceae: a relictual rain forest family. Annals of Botany 108:347-357.

O'Neill, G. A., A. Hamann, and T. Wang. 2008. Accounting for population variation improves estimates of the impact of climate change on species' growth and distribution. Journal of Applied Ecology 45:1040-1049.

Oney, B., B. Reineking, G. O’Neill, and J. Kreyling. 2013. Intraspecific variation buffers projected climate change impacts on Pinus contorta. Ecology and Evolution 3: 437-449.

Parmesan, C., S. Gaines, L. Gonzalez, D. M. Kaufman, J. Kingsolver, A. T. Peterson, and R. Sagarin. 2005. Empirical perspectives on species borders: from traditional biogeography to global change. Oikos 108:58-75. 
Parmesan, C., and G. Yohe. 2003. A globally coherent fingerprint of climate change impacts across natural systems. Nature 421:37-42.

Périé, C., S. de Blois, M.-C. Lambert, and N. Casajus. 2014. Effets anticipés des changements climatiques sur l'habitat des espèces ligneuses au Québec. Mémoire de recherche forestière n.173. Government of Québec, Ministère des Ressources naturelles, Direction de la recherche forestière, Québec, Québec, Canada.

Pither, J. 2003. Climate tolerance and interspecific variation in geographic range size. Proceedings of the Royal Society B 270:475-481.

Porter, R. B., T. Lacourse, B. J. Hawkins, and A. Yanchuk. 2013. Adaptive variation in growth, phenology, cold tolerance and nitrogen fixation of red alder (Alnus rubra Bong.). Forest Ecology and Management 291:357-366.

Price, T. D., and M. Kirkpatrick. 2009. Evolutionarily stable range limits set by interspecific competition. Proceedings of the Royal Society B 276:1429-1434.

Randin, C. F., J. Paulsen, Y. Vitasse, C. Kollas, T. Wohlgemuth, N. E. Zimmermann, and C. Körner. 2013. Do the elevational limits of deciduous tree species match their thermal latitudinal limits? Global Ecology and Biogeography 22:913-923.

Rawal, D. S., S. Kasel, M. R. Keatley, C. Aponte, and C. R. Nitschke. 2014. Environmental effects on growth phenology of co-occurring Eucalyptus species. International Journal of Biometeorology 58:427-442.

Rehfeldt, G. E., C. C. Ying, D. L. Spittlehouse, and D. A. Hamilton Jr. 1999. Genetic responses to climate in Pinus contorta: niche breadth, climate change, and reforestation. Ecological Monographs 69:375-407.

Reich, P. B., B. D. Kloeppel, D. S. Ellsworth, and M. B. Walters. 1995. Different photosynthesis-nitrogen relations in deciduous hardwood and evergreen coniferous tree species. Oecologia 104:24-30.

Reich, P. B., and J. Oleksyn. 2008. Climate warming will reduce growth and survival of Scots pine except in the far north. Ecology Letters 11:588-597.

Reich, P. B., K. M. Sendall, K. Rice, R. L. Rich, A. Stefanski, S. E. Hobbie, and R. A. Montgomery. 2015. Geographic range predicts photosynthetic and growth response to warming in co-occurring tree species. Nature Climate Change $5: 148-152$.

Renwick, K. M., and M. E. Rocca. 2015. Temporal context affects the observed rate of climate-driven range shifts in tree species. Global Ecology and Biogeography 24:44-51.

Ricard, J.-P., C. Messier, S. Delagrange, and M. Beaudet. 2003. Do understory sapling respond to both light and belowground competition? A field experiment in a north-eastern American hardwood forest and a literature review. Annals of Forest Science 60:749-756.

Salisbury, E. J. 1926. The geographical distribution of plants in relation to climatic factors. Geographical Journal 67:312-335.

Samis, K. E., and C. G. Eckert. 2009. Ecological correlates of fitness across the northern geographic range limit of a Pacific Coast dune plant. Ecology 90:3051-3061.

Savage, J. A., and J. Cavender-Bares. 2013. Phenological cues drive an apparent trade-off between freezing tolerance and growth in the family Salicaceae. Ecology 94:1708-1717.

Savva, Y., B. Denneler, A. Koubaa, F. Tremblay, Y. Bergeron, and M. G. Tjoelker. 2007. Seed transfer and climate change effects on radial growth of jack pine populations in a common garden in Petawawa, Ontario, Canada. Forest Ecology and Management 242:636-647.

Sax, D. F. 2001. Latitudinal gradients and geographic ranges of exotic species: implications for biogeography. Journal of Biogeography 28:139-150.
Sexton, J. P., P. J. McIntyre, A. L. Angert, and K. J. Rice. 2009. Evolution and ecology of species range limits. Annual Review of Ecology, Evolution, and Systematics 40:415-436.

Shaw, R. G., G. A. J. Platenkamp, F. H. Shaw, and R. H. Podolsky. 1995. Quantitative genetics response to competitors in Nemophila menziesii: a field experiment. Genetics 139:397-406

Speed, J. D. M., G. Austrheim, A. J. Hester, and A. Mysterud. 2010. Experimental evidence for herbivore limitation of the treeline. Ecology 91:3414-3420.

St. Clair, S. B., and J. P. Lynch. 2005. Element accumulation patterns of deciduous and evergreen tree seedlings on acid soils: implications for sensitivity to manganese toxicity. Tree Physiology 25:85-92.

St. Clair, S. B., W. E. Sharpe, and J. P. Lynch. 2008. Key interactions between nutrient limitation and climatic factors in temperate forests: a synthesis of the sugar maple literature. Canadian Journal of Forest Research 38:401-414.

Stanton-Geddes, J., P. Tiffin, and R. G. Shaw. 2012. Role of climate and competitors in limiting fitness across range edges of an annual plant. Ecology 93:1604-1613.

Stueve, K. M., R. E. Isaacs, L. E. Tyrrell, and R. V. Densmore. 2011. Spatial variability of biotic and abiotic tree establishment constraints across a treeline ecotone in the Alaska Range. Ecology 92:496-506.

Svenning, J.-C., et al. 2014. The influence of interspecific interactions on species range expansion rates. Ecography 37:1198-1209.

Sykes, M. T., I. C. Prentice, and W. Cramer. 1996. A bioclimatic model for the potential distributions of north European tree species under present and future climates. Journal of Biogeography 23:203-233.

Thornthwaite, C. W. 1948. An approach toward a rational classification of climate. Geographical Review 38:55-94.

Thuiller, W., S. Lavorel, M. B. Araújo, M. T. Sykes, and I. C. Prentice. 2005. Climate change threats to plant diversity in Europe. Proceedings of the National Academy of Sciences USA 102:8245-8250.

Tilman, D. 1988. Plant strategies and the dynamics and structure of plant communities. Princeton University Press, Princeton, New Jersey, USA.

Van der Veken, S., J. Rogister, K. Verheyen, M. Hermy, and R. Nathan. 2007. Over the (range) edge: a 45-year transplant experiment with the perennial forest herb Hyacinthoides non-scripta. Journal of Ecology 95:343-351.

Vergeer, P., and W. E. Kunin. 2013. Adaptation at range margins: common garden trials and the performance of Arabidopsis lyrata across its northwestern European range. New Phytologist 197:989-1001.

Vetaas, O. R. 2002. Realized and potential climate niches: a comparison of four Rhododendron tree species. Journal of Biogeography 29:545-554.

Vitasse, Y., G. Hoch, C. F. Randin, A. Lenz, C. Kollas, J. F. Scheepens, and C. Körner. 2013. Elevational adaptation and plasticity in seedling phenology of temperate deciduous tree species. Oecologia 171:663-678.

Walker, K. V., M. B. Davis, and S. Sugita. 2002. Climate change and shifts in potential tree species range limits in the Great Lakes region. Journal of Great Lakes Research 28: 555-567.

Walters, M. B., and P. B. Reich. 1997. Growth of Acer saccharum seedlings in deeply shaded understories of northern Wisconsin: effects of nitrogen and water availability. Canadian Journal of Forest Research 27:237-247.

Walters, M. B., and P. B. Reich. 2000. Seed size, nitrogen supply and growth rate affect tree seedling survival in deep shade. Ecology 81:1887-1901. 
Walters, M. B., J. L. Willis, and K. W. Gottschalk. 2014. Seedling growth responses to light and mineral $\mathrm{N}$ form are predicted by species ecologies and can help explain tree diversity. Canadian Journal of Forest Research 44: 1356-1368.

Walther, G.-R., S. Berger, and M. T. Sykes. 2005. An ecological 'footprint' of climate change. Proceedings of the Royal Society B 272:1427-1432.

Wang, T., G. A. O'Neill, and S. N. Aitken. 2010. Integrating environmental and genetic effects to predict responses of tree populations to climate. Ecological Applications 20:153-163.

Weih, M. 2009. Genetic and environmental variation in spring and autumn phenology of biomass willows (Salix spp.): effects on shoot growth and nitrogen economy. Tree Physiology 29:1479-1490.

Welden, C. W., and W. L. Slauson. 1986. The intensity of competition versus its importance: an overlooked distinction and some implications. Quarterly Review of Biology 61:23-44.

Welk, A., E. Welk, and H. Bruelheide. 2014. Biotic interactions overrule plant responses to climate, depending on the species' biogeography. PLoS ONE 9:e111023.

Williams, J. W., B. N. Shuman, T. Webb III, P. J. Bartlein, and P. L. Leduc. 2004. Late-Quaternary vegetation dynamics in North America: scaling from taxa to biomes. Ecological Monographs 74:309-334.

Wipf, S., C. Rixen, and C. P. H. Mulder. 2006. Advanced snowmelt causes shift towards positive neighbour interactions in a subarctic tundra community. Global Change Biology 12: 1496-1506.

Wisz, M. S., et al. 2013. The role of biotic interactions in shaping distributions and realised assemblages of species: implications for species distribution modeling. Biological Reviews 88:15-30.

Woodall, C. W., C. M. Oswalt, J. A. Westfall, C. H. Perry, M. D. Nelson, and A. O. Finley. 2009. An indicator of tree migration in forests of the eastern United States. Forest Ecology and Management 257:1434-1444.

Woodward, F. I. 1987. Climate and plant distribution. Cambridge University Press, Cambridge, UK.

Woodward, F. I. 1990. The impact of low temperatures in controlling the geographical distribution of plants. Philosophical Transactions of the Royal Society B 326:585-593.

Woodward, F. I., and C. D. Pigott. 1975. The climatic control of the altitudinal distribution of Sedum rosea (L.) Scop. and S. elephium L. I. Field observations. New Phytologist 74: 323-334

Wright, A., S. A. Schnitzer, and P. B. Reich. 2014. Living close to your neighbors: the importance of both competition and facilitation in plant communities. Ecology 95:2213-2223.

Yetter, T. C., and J. R. Runkle. 1986. Height growth rates of canopy tree species in southern Appalachian gaps. Castanea 51:157-167.

Zohner, C. M., and S. S. Renner. 2014. Common garden comparison of the leaf-out phenology of woody species from different native climates, combined with herbarium records, forecasts long-term change. Ecology Letters 17:1016-1025.

SUPPORTING INFORMATION

Additional Supporting Information may be found online at: http://onlinelibrary.wiley.com/doi/10.1002/ecm.1237/full

Data Availability

Data associated with this paper are available in figshare: https://doi.org/10.6084/m9.figshare.3976599 